Max-Planck-Institut für demografische Forschung

Max Planck Institute for Demographic Research

Konrad-Zuse-Strasse 1 - D-18057 Rostock - GERMANY

Tel +49 (0) 3812081 - 0; Fax +49 (0) 3812081 - 202;

http://www.demogr.mpg.de

MPIDR WORKING PAPER WP 2011-015

SEPTEMBER 2011

\title{
The Role of Demography on Per Capita Output Growth and Saving Rates
}

Miguel Sanchez-Romero (msanchez@demogr.mpg.de)

This working paper has been approved for release by: Michaela Kreyenfeld (kreyenfeld@demogr.mpg.de), Acting Deputy Head of the Laboratory of Economic and Social Demography.

(C) Copyright is held by the authors.

Working papers of the Max Planck Institute for Demographic Research receive only limited review. Views or opinions expressed in working papers are attributable to the authors and do not necessarily reflect those of the Institute. 


\title{
The Role of Demography on Per Capita Output Growth and Saving Rates *
}

\author{
Miguel Sanchez-Romero \\ Max Planck Institute for Demographic Research
}

September 13, 2011

\begin{abstract}
Computable OLG growth models and "convergence models" differ in their assessment of the extent to which demography influences economic growth. In this paper, I show that computable OLG growth models produce results similar to those of convergence models when more detailed demographic information is used. To do so, I implement a general equilibrium overlapping generations model to explain Taiwan's economic miracle during the period 1965-2005. I find that Taiwan's demographic transition accounts for $22 \%$ of per capita output growth, $16.4 \%$ of the investment rate, and $18.5 \%$ of the savings rate for the period 1965-2005. Decomposing the demographic effect into its components, I find that fertility alone explains the impact of demographic changes in per capita output growth, while both fertility and mortality explain investment and saving rates. Assuming a small-open economy, I find that investment rates increase with more rapid population growth, while saving rates follows the dependence hypothesis (Coale and Hoover, 1958). Under a closed-economy, the population growth rate has a negative influence on economic growth.
\end{abstract}

JEL Classification Numbers: E21; J1; O11

Keywords: Demography; Income growth; Saving rate; Taiwan; Overlapping generations.

\footnotetext{
*I am extremely thankful to Ronald D. Lee, Andrew Mason, Paul Lau, Bernardo Queiros, P. C. Roger Cheng, Ester González Prieto, Fanny Kluge, Gustav Oeberg and two anonymous referees for giving me very useful comments, suggestions, and ideas. I am also grateful to the Max Planck Society, the Center on Economics and Demography of Aging (CEDA), and the Department of Demography at UC Berkeley for their support and hospitality. This work received institutional support in its earliest stage from the Fulbright Commission (reference \# 2007-0445).
} 


\section{Introduction}

In the second half of the 20th century, the world experienced income growth rates never seen before, as well as an accelerated decline in mortality and fertility (Lee, 2003). East-Asia benefited from these two processes more than any other region in the world (Mason, 2001). Indeed, the East Asian nations were the first countries after World War II to make a rapid demographic transition from high mortality and high fertility to low mortality and low fertility (Feeney and Mason, 2001). During the same period, nine of these economies were among the countries with the highest per capita GDP growth (Barro and Sala-i-Martín, 2004). As a result of the simultaneity between economic and demographic processes in the East Asian nations and elsewhere, studies that seek to explain the influence of demography on economic growth have attracted considerable attention.

An influential article by Coale and Hoover (1958) shaped the first contemporary models. They posited that economies with a high total dependency ratio should present low or negative saving rates; and that, conversely, an economy with a low total dependency ratio should have high saving rates. However, the empirical results of studies testing the negative relationship between saving rates and the dependency ratio have been mixed. Some analyses have confirmed the dependency hypothesis (Leff, 1969; Modigliani, 1970; Fry and Mason, 1982; Mason, 1988; Higgins and Williamson, 1997), while others, using similar and different econometric techniques, have not provided conclusive results (Goldberger, 1973; Ram, 1982; Gersovitz, 1988).

In the 1990s, Bloom and Williamson (1998), using growth regression models (also known as convergence models), showed that East Asia's economic miracle was in part a consequence of demographics. They convincingly demonstrated that, after the first stage of the demographic transition, when fertility starts to decline, per capita productive capacity is boosted because the working-age population grow faster than the dependent population, leading to the so-called first demographic dividend. In the same line of research, Kelley and Smith (2005) decomposed the demographic effect into a productivity component and a translation component. They found that, when the two components are combined, demography accounts for $20 \%$ of per capita output growth world-wide. Unfortunately, because the growth regression models suffer from endogeneity problems in the factor accumulation variables (Feyrer, 2007), researchers prefer to use growth models with microfoundations or general equilibrium overlapping generation models.

Thus far, computable OLG growth models with fixed household size have found no significant effect of demography on Japan's national saving rate (Hayashi and Prescott, 2002; Chen et al., 2006, 2007). However, since in these models fertility does not affect individuals' utility function and budget constraints, these results could have been anticipated (d'Albis, 2007; Lau, 2009). More relevant are the results obtained by Braun et al. (2009) for Japan. By introducing changing family size and endogenously determined interest rates, they found a small effect of demography on economic growth during the last four decades of the 20th century. Nevertheless, Braun et al. (2009) also found that the demographic effect will become progressively more important with population aging. Similar findings have been obtained by Ríos-Rull (2001) for Spain and by Krueger and Ludwig (2006) for the world, in contrast to Poterba (2001). Using an OLG model with youth dependency and a fixed interest rate, Lee et al. $(2000,2001,2003)$ found a significant effect of demography on Taiwan's saving rates; and, more recently, Curtis et al. (2011) showed that China's high saving rates are primarily driven by changes in family size. These results are consistent with those of (Attanasio and Weber, 2010; Browning and Lusardi, 1996). Unfortunately, since Lee et al. $(2000,2001,2003)$ and Curtis et al. (2011) fixed the interest rate, and hence the way that demography affects the productivity component, the results obtained by Curtis et al. (2011) are not 
directly comparable to those obtained by Braun et al. (2009). Nonetheless, despite the lack of consensus, there is one clear conclusion from the most recent computable OLG growth models: the introduction of more realistic demography into OLG models increases the economic-demographic connection.

In this paper, I reconcile the computable OLG growth models with the growth regression models using the Taiwanese economy. ${ }^{1}$ My reason for doing so is simple. According to the first demographic dividend, an increase in the share of the working-age population promotes economic growth. Hence, the economic growth does not start until the first post-baby boom cohort has entered the labor market (i.e., in general, 20 years after the onset of the decline in fertility). However, the most common approach in computable OLG growth models is to run counterfactual experiments, fixing vital rates at the beginning of the economic analysis (Hayashi and Prescott, 2002; Chen et al., 2006, 2007; Braun et al., 2009), rather than fixing the rates at least one generation before. As a consequence, the effect of demography on economic growth is underestimated.

To illustrate this point, I use a computable general equilibrium model inhabited by 100 overlapping generations. In line with Chen et al. $(2006,2007)$ and Braun et al. (2009), I assume that individuals consume and save according to the life-cycle hypothesis of Modigliani and Brumberg (1954), and face mortality risk and borrowing constraints (Yaari, 1965). Bequests are unintentional and are received from the expected parent. In addition, the model setup incorporates important public and private transfers such as public consumption, childrearing costs, and familial old-age support. In order to control for the effect of the educational transition in Taiwan, I consider that individuals differ by educational attainment. ${ }^{2}$ Data on labor efficiency by educational group, as well as on educational distribution by birth cohort for Taiwan, are taken from Huang (2001). Thus, the productivity measure takes into account quality and age differences in the physical and human capital stock (Feyrer, 2007).

In order to perform the procedure suggested in this paper for estimating the effect of demography on economic growth, two additional requirements must be met. First, OLG growth models need demographic data dating back before the economic information is available, which limits the number of countries for which this analysis can be conducted. Second, because we will not, in general, have an initial wealth profile, the initial steady-state will have to be derived by starting the simulation with a stable population. ${ }^{3}$ In seeking to meet these two additional requirements, Taiwan is of special interest. For Taiwan, we have access to reliable economic data since 1951 and sufficient demographic information during a large part of the country's demographic transition. Moreover, Taiwan is also interesting because it experienced the most rapid economic growth of any country for the period 1960-2000. In 1960, the real per capita GDP was $\$ 1.430$; by 2000, it had risen by a factor of 17 (Barro and Sala-i-Martín, 2004). To overcome the lack of information on family size by age and over time I introduce two demographic methods widely-used in population reconstruction: Inverse Projection (IP) and Generalized Inverse-Projection (GIP) (Lee, 1985; Oeppen, 1993).

The results obtained from simulations are in line with the population revisionist position. I find that population accounts for $22 \%$ of Taiwan's per capita output growth, $16.4 \%$ of its investment rate, and $18.5 \%$ of its saving rate for the period 1965-2005. In line with previous literature, counterfactual experiments

\footnotetext{
${ }^{1}$ This result can be extended to other countries. The reason for focusing on Taiwan, rather than on Japan, is because Taiwan started the demographic transition in the 20th century.

${ }^{2}$ Taiwan's demographic transition started in the 1920s, 40 years before the economic boom. In 1944, the constitution of the Republic of China established six years of compulsory education, and this period was extended to nine years in 1968. As a result, the proportion of illiterate and self-educated people changed from 40\% in 1940 to almost 0\% in 1970 (Huang, 2001).

${ }^{3}$ All requirements for a steady-state equilibrium will then be satisfied.
} 
show that fertility alone explains the impact of demographic changes in per capita output growth, while mortality has no significant influence throughout the period analyzed (Bloom and Freeman, 1986; Brander and Dowrick, 1994; Barlow, 1994; Kelley and Schmidt, 1995; Bloom and Williamson, 1998). However, the effect of demography on saving and investment is somehow less straightforward. Assuming a small-open economy, I find that investment rates increase with more rapid population growth, while saving rates are explained by the dependence hypothesis (Coale and Hoover, 1958; Williamson and Higgins, 2001). By contrast, under a closed-economy, lower mortality and lower fertility have the opposite effect on saving and investment rates.

The rest of the paper is organized as follows. Section 2 introduces the model setup. In Section 3, I present the economic and demographic data and discuss the calibration process. In Section 4, I demonstrate that this model is capable of reproducing Taiwan's national accounts data from 1965 to 2005. Section 5 is devoted to showing and explaining the influence of demography on output per capita, investment, and saving rates using several counterfactual experiments. Concluding remarks are made in Section 6 .

\section{Model}

\subsection{Demographics}

Time is discrete. Let $t \in\left\{t_{0}, t_{0}+1, \ldots, T\right\}$ denote time, where $t_{0}$ and $T$ are the first and last years at which the population is computed. The economy is comprised of a finite number of individuals at each time $t$. Individuals can live at most $\Omega$ years (maximum longevity). Let $x$ denote age, $x \in\{0, \ldots, \Omega\}$. Lifetime uncertainty is described by the survival function $l_{t, x}$, where

$$
l_{t, x}=\prod_{z=0}^{x-1} \pi_{t-x+z, z}
$$

is the survival probability at age $x$ in year $t, l_{, 0}=1, l_{, \Omega}=0$, and $\pi_{t, x}$ is the conditional probability (of being alive at age $x$ in year $t$ ) of surviving to age $x+1$ (with $\pi_{\cdot, x}=0$, for all $x \geq \Omega$ ).

Let $N_{t}$ denote the total population size in year $t$ and $N_{t, x}$ be the size of the population at age $x$ in year $t$. I assume a closed population whose law of motion (or "balancing equation") is given by ${ }^{4}$

$$
N_{t+1}=N_{t}+B_{t}-D_{t} .
$$

Population at time $t+1$ is given by the population in year $t$ plus the total number of births in year $t$, denoted $B_{t}$, less the total number of deaths during the year $D_{t}$. The dynamics of the population can be written in matrix notation using a Leslie matrix (Leslie, 1945; Preston et al., 2002)

$$
\mathbf{N}(t+1)=\mathbf{L}(t) \mathbf{N}(t),
$$

with

$$
\begin{aligned}
& \Gamma_{1, x}(t)=\frac{L_{t, 0}}{2 l_{t, 0}}\left(f_{t, x}+f_{t, x+1} \frac{L_{t, x+1}}{L_{t, x}}\right) f_{f a b}, \\
& \Gamma_{x+1, x}(t)=\frac{L_{t, x+1}}{L_{t, x}}, \text { for } x \in\{1, \ldots, \Omega-1\} \text { at time } t,
\end{aligned}
$$

\footnotetext{
${ }^{4}$ The population of Taiwan was reconstructed using historical data from 1906 to 2010. During the first half of the 20th century, Taiwan experienced massive in- and out-migration flows, which are explained in Section 3.1. I have run simulations under both closed and open populations. However, similar to Lee et al. (2000), I use a closed population because the results do not change significantly and are less noisy.
} 
where $L_{t, x}=\frac{l_{t, x}+l_{t, x+1}}{2}$ is the person years lived by the cohort between ages $x$ and $x+1$ in period $t$, $f_{t, x}$ is the age-specific fertility rate at age $x$ in year $t, f_{f a b}$ is the fraction of females at birth (I assume $f_{f a b}=0.4886$, which is the standard value in the demographic literature).

\section{$2.2 \quad$ Firm's problem}

Firms combine capital and labor using a Cobb-Douglas constant returns to scale production function to produce a single good, which can either be saved or consumed,

$$
Y_{t}=K_{t}^{\alpha}\left(\Gamma_{t} H_{t}\right)^{1-\alpha},
$$

where $Y_{t}$ is output, $K_{t}$ is the stock of capital, $H_{t}$ is the effective aggregate labor input, and $\Gamma_{t}$ is laboraugmenting technological progress. Aggregate capital stock evolves according to the law of motion:

$$
K_{t+1}=K_{t}\left(1-\delta_{t}\right)+I_{t},
$$

where $\delta_{t}$ is the depreciation rate of capital and $I_{t}$ is aggregate gross investment. We assume that firms pay corporate taxes and maximize their net cash flow by renting capital and hiring labor from households in competitive markets at the rates $r_{t}$ and $w_{t}$, respectively. The net cash flow of the firm is given by

$$
X_{t}=Y_{t}-w_{t} H_{t}-I_{t} .
$$

Thus, labor and capital inputs are chosen by firms according to the first-order conditions:

$$
\begin{aligned}
r_{t}+\delta_{t} & =\alpha K_{t}^{\alpha-1}\left(\Gamma_{t} H_{t}\right)^{1-\alpha}, \\
w_{t} & =(1-\alpha) \Gamma_{t} K_{t}^{\alpha}\left(\Gamma_{t} H_{t}\right)^{-\alpha} .
\end{aligned}
$$

\subsection{Household's problem}

All households have one adult, or household head, and a number of dependent children with ages ranging from 0 to 19. The number of children raised by the household head varies over time, either because of mortality and fertility or because children leave their parental home, setting up a new household, at age $20\left(T_{w}\right)$. If the household head dies, the economic unit vanishes and the surviving dependent offspring are borne by a different household with similar characteristics. The additional burden for the new household is mitigated by the receipt of the assets of the deceased adult. We assume that individuals exogenously supply their labor force $h_{t, x}$ until retirement at age $60\left(T_{r}\right) .{ }^{5}$ Labor in efficiency units at age $x$ is conditional on the educational attainment $\varepsilon_{x}^{j}{ }^{6}$ In line with Díaz-Giménez and Díaz-Saavedra (2009), I assume that when individuals enter the labor market, they are randomly assigned to an educational level group according to an educational distribution by birth cohort (see Figure 3(b) in Section 3.2).

I assume that household heads are selfish and begin with zero assets $a_{t, T_{w}}=0$. I also assume that there is no annuity market. Under this setup, it is well known that individuals will leave accidental

\footnotetext{
${ }^{5}$ Since during the period analyzed unemployment rates were low in Taiwan (close to $2 \%$ ), savings are not affected by labor uncertainty. Therefore, for simplicity, I have taken as $h_{t, x}$ values actual employment rates by age.

${ }^{6}$ Taiwan experienced a dramatic increase in human capital accumulation for cohorts born between the 1940s and the 1970s (Huang, 2001). In order to capture the effect that human capital heterogeneity has on economic growth, I have included six different educational levels $\mathcal{E}=\{$ Illiterate and self-educated, elementary school, junior middle school, senior high school, vocational school, and college and above\}, where $j \in \mathcal{E}$. The age-specific labor productivity indexes by educational attainment are calculated based on Huang (2001, Table 11.3).
} 
bequests at death (Yaari, 1965). Preferences are concave (i.e., $u^{\prime}>0, u^{\prime \prime}<0$ ), additive, and identical among household heads. Thus, household heads solve the following Bellman equation:

$$
V_{x}^{j}\left(a_{t, x}^{j}\right)=\max _{c}\left\{u\left(c_{t, x}^{j}\right)+\beta \pi_{t, x} V_{x+1}^{j}\left(a_{t+1, x+1}^{j}\right)\right\}
$$

subject to

$$
c_{t, x}^{j}+a_{t+1, x+1}^{j}+w_{t} \chi_{x}+\tau_{t, x}^{j} \leq\left(1+r_{t}\right)\left(a_{t, x}^{j}+b_{t, x}\right)+y_{l t, x}^{j}+\phi_{t, x}^{j},
$$

where

$$
\begin{gathered}
\tau_{t, x}^{j}=\tau_{c t} c_{t, x}^{j}\left(1+\lambda_{t, x}^{c}\right)+\tau_{l t} w_{t} \varepsilon_{x}^{j} h_{t, x}+\tau_{k t} r_{t}\left(a_{t, x}^{j}+b_{t, x}\right), \\
y_{l t, x}^{j}= \begin{cases}\left(1-\tau_{s t}\right) w_{t} \varepsilon_{x}^{j} h_{t, x} & \text { if } T_{w} \leq x<T_{r}, \\
b r_{t, x}^{j} & \text { if } T_{r} \leq x<\Omega,\end{cases}
\end{gathered}
$$

and

$$
\phi_{t, x}^{j}= \begin{cases}-\tau_{t, x}^{o a s}\left(1-\tau_{l t}\right) w_{t} \varepsilon_{x}^{j} h_{t, x}-w_{t} \lambda_{t, x}^{\chi}-\lambda_{t, x}^{c} c_{t, x}^{j} & \text { if } T_{w} \leq x<T_{r}, \\ \pi^{o a s} \bar{y}_{t, x}-w_{t} \lambda_{t, x}^{\chi}-\lambda_{t, x}^{c} c_{t, x}^{j} & \text { if } T_{r} \leq x<\Omega,\end{cases}
$$

with $c_{t, x} \geq 0$ and the boundary conditions $a_{t-x+T_{w}, T_{w}}=0$ and $a_{t-x+\Omega, \Omega} \geq 0$.

In this problem, there is one state variable $a_{t, x}^{j}$, or assets held by an individual with education $j$ at age $x$ in year $t$, and one control variable $c_{t, x}^{j}$, or consumption at age $x$ in year $t$ of a household head with education $j$. $\beta$ is the subjective discount factor, $w_{t} \chi_{x}$ is private expenditures on own education and health care, and $\tau_{t, x}^{j}$ is total household taxes paid. The flow budget constraint (11) states that asset holdings at the end of the period increase because of the capitalization of previous asset holdings $\left(1+r_{t}\right) a_{t, x}$, bequests received $\left(1+r_{t}\right) b_{t, x}$, labor income (net of social contributions) while in the labor force or retirement benefits if retired $y_{l t, x}^{j}$, and net non-capital familial transfers received $\phi_{t, x}^{j}$. On the other hand, $a_{t+1, x+1}$ decreases because of the household head consumption $c_{t, x}^{j}$, private expenditures on own education and health care $\chi_{x}$, and total household taxes paid to the government on consumption $\tau_{c t} c_{t, x}^{j}\left(1+\lambda_{t, x}^{c}\right)$ and labor $\tau_{l t} w_{t} \varepsilon_{x}^{j} h_{t, x}$, where $\lambda_{t, x}^{c}$ is the number of dependent children, in units of equivalent adult consumers, within a household whose head is $x$ years old at time $t$.

Familial transfers are comprised of familial transfer wealth (i.e., bequests) and non-capital familial transfers. To realistically model inheritances, I assume that the bequest is distributed among the adult surviving children. If there are no surviving adult offspring, the bequest is distributed within the cohort. Non-capital familial transfers, $\phi$, includes: i) childrearing costs (i.e., $\lambda_{t, x}^{c} c_{t, x}^{j}$ ); ii) private health care and education expenditures given $w_{t} \lambda_{t, x}^{\chi}$ and received $w_{t} \chi_{x}$; and iii) familial old-age support paid by adult children to the retired parent, where $\tau_{t, x}^{\text {oas }}$ is the fraction of labor income of an individual of age $x$ in year $t$ allocated to the financial support of her elderly parent, $\pi^{o a s}$ is the familial old-age support rate, which is a fraction of the average labor income of the adult offspring $\bar{y}_{t, x}{ }^{7}$

\subsection{Government}

The government provides health care, education, and other goods and services (infrastructure, defense, etc.). Total government expenditure is

$$
G_{t}=\eta_{t} Y_{t}
$$

\footnotetext{
${ }^{7}$ In Taiwan, the majority of elderly people live with their children, and the country has one of the highest familial elderly support expenditures per family member (Lee et al., 1994; Deaton and Paxson, 2000).
} 
where $\eta_{t}$ is the fraction of public consumption relative to output in year $t$. To finance these expenditures, the government levies taxes on labor $\left(T_{l t}=\tau_{l t} w_{t} H_{t}\right)$, capital income $\left(T_{k t}=\tau_{k t} r_{t} K_{t}\right)$, and consumption $\left(T_{c t}=\tau_{c t} C_{t}\right)$, or, equivalently

$$
T_{t}=\sum_{x=T_{w}}^{\Omega-1} N_{t+1, x+1} \int_{\mathcal{E}} \tau_{t, x}^{j} d E_{t-x},
$$

where $E_{t}$ is the educational distribution of children born in year $t$ (see Figure $\left.3(\mathrm{~b})\right) .{ }^{8} \mathrm{I}$ assume that the government budget is balanced at all times

$$
T_{t} \equiv T_{l t}+T_{k t}+T_{c t}=G_{t}
$$

In order to guarantee that Equation (17) holds, I assume that consumption taxes finance the gap between public consumption expenditures and capital income tax and labor income tax revenues.

Our government also provides retirement benefits. I assume that pension benefits are proportional to the average wage during its last three years, denoted by $N_{b}$, and are constant during retirement. The benefits received by a retiree are given by

$$
b r_{t, x}^{j}=\psi \frac{1}{N_{b}} \sum_{i=T_{r}-N_{b}}^{T_{r}-1} \varpi w_{t} \varepsilon_{x}^{j} h_{t, x}, \text { for } x \geq T_{r},
$$

where $\psi$ is the replacement ratio of the pension benefit and $\varpi$ is the proportion of income insured. To finance the aggregate pension benefits claimed, the government levies social contributions on current workers (i.e., PAYG system) as follows

$$
\tau_{s t} \sum_{x=T_{w}}^{T_{r}-1} N_{t+1, x+1} \int_{\mathcal{E}} w_{t} \varepsilon_{x}^{j} h_{t, x} d E_{t-x}=\sum_{x=T_{r}}^{\Omega-1} N_{t+1, x+1} \int_{\mathcal{E}} b r_{t, x}^{j} d E_{t-x},
$$

where $\tau_{s t}$ is the social contribution rate in year $t$.

\subsection{Recursive competitive equilibrium}

Given $\left\{\Gamma_{t}, \delta_{t}, \mathbf{L}_{t}, \mathbf{N}_{t}, E_{t},\left\{h_{t, x}\right\}_{x=0}^{\Omega}\right\}_{t=t_{0}}^{T}$, a recursive competitive equilibrium with transfers is a set of household policy functions $\left\{\left\{c_{t, x}^{j}, a_{t, x}^{j}\right\}_{j \in \mathcal{E}}\right\}_{x=0}^{\Omega}$, familial transfers $\left\{\chi_{x}, b_{t, x},\left\{\phi_{t, x}^{j}\right\}_{j \in \mathcal{E}}\right\}_{x=0}^{\Omega}$ over $t \in\left\{t_{0}, \ldots, T\right\}$, government policy functions $\left\{G_{t}, \tau_{c t}, \tau_{k t}, \tau_{l t}, \tau_{s t}, N_{b}, \psi, \varpi\right\}_{t=t_{0}}^{T}$, and factor prices $\left\{w_{t}, r_{t}\right\}_{t=t_{0}}^{T}$ such that

- household policy functions solve the dynamic program (10)-(14), given the factor prices, government policy functions, and familial transfers.

- the sum of familial transfers given equals the sum of familial transfers received:

$$
\begin{gathered}
\sum_{x} b_{t, x} N_{t+1, x+1}=\sum_{x}\left(1-\pi_{t, x}\right) N_{t, x} \int_{\mathcal{E}} a_{t, x}^{j} d E_{t-x} \\
\sum_{x} N_{t+1, x+1} \int_{\mathcal{E}} \phi_{t, x}^{j} d E_{t-x}=0
\end{gathered}
$$

- factor prices equal their marginal productivities, so that (8) and (9) hold.

- the government's budget constraints (17) and (19) are satisfied in each period.

\footnotetext{
${ }^{8}$ Let $E_{t}(j)$ be the cumulative distribution function of the educational attainment of an individual born in year $t$. Thus, for any $j \in \mathcal{E}, E_{t}(j)$ is defined as $\operatorname{Pr}$ (education of an individual born in year $t$ is equal to or less than $j$ ).
} 
- the stock of capital and effective labor input are given by:

$$
\begin{gathered}
K_{t}=\sum_{x=T_{w}}^{\Omega-1} N_{t, x} \int_{\mathcal{E}} a_{t, x}^{j} d E_{t-x}-F_{t}, \\
H_{t}=\sum_{x=T_{w}}^{\Omega-1} N_{t+1, x+1} \int_{\mathcal{E}} \epsilon_{t, x}^{j} h_{t, x} d E_{t-x} .
\end{gathered}
$$

where $F_{t}$ is the value of internationally traded bonds.

- the commodity market clears:

$$
\mathrm{GDP}_{t}+r_{t} F_{t}=C_{t}+G_{t}+I_{t}
$$

where $C_{t}$ is aggregate consumption and $\mathrm{GDP}_{t}=Y_{t}+T_{c t}$ is the gross domestic product in year $t$.

\section{Data and calibration}

The point of departure of this paper is that demographic data have not been fully exploited. As a result, an underestimation of the effect of demography on economic growth has generally been made in overlapping generations models. The first reason for considering a long time series of demographic data is that it is necessary to have a stable population to guarantee both an initial and a final steady state economy. This implies that we need to derive an initial stable population that evolves consistently with actual population data. It should be noted that, by starting and finishing the simulation with a stable population, the model finds both the initial and the final steady state interest rates. Consequently, I do not need to impose an initial wealth profile, which might not be consistent with the household's problem. The second reason for using a long time series is that, in order to assess the effect of demographic changes on economic growth, we need demographic data that date back at least one generation before the economic data are available. This point will be shown in Section 4. Next, I explain the calibration process of demographic and economic data.

\subsection{Demography}

I combine two demographic methods widely used in population reconstruction: Inverse Projection (IP) and Generalized Inverse Projection (GIP) (Lee, 1985; Oeppen, 1993). GIP is a non-linear optimization that produces constrained demographic projections with a priori information (Oeppen, 1993). ${ }^{9}$ GIP

\footnotetext{
${ }^{9}$ Since the economic model does not distinguish between gender, parity, region, etc.; I use a simplified version of a GIP model that matches the specific characteristics of this economic model. The objective function used to solve the problem is:

$$
\begin{aligned}
\min _{\left\{\left\{\alpha_{t}^{i}, \gamma_{t}^{i}\right\}_{i=0}^{2}\right\}_{t=t_{0}}^{T}} \sum_{t \in \mathbb{D}}\left(\frac{D_{t}-\hat{D}_{t}}{D_{t}}\right)^{2}+\sum_{t \in \mathbb{B}}\left(\frac{B_{t}-\hat{B}_{t}}{B_{t}}\right)^{2}+\sum_{t \in \mathbb{N}}\left(\frac{N_{t}-\hat{N}_{t}}{N_{t}}\right)^{2}+\sum_{t \in \mathbb{E}}\left(\frac{e_{t}-\hat{e}_{t}}{e_{t}}\right)^{2} \\
+\sum_{t \in \mathbb{T}}\left(\frac{t f r_{t}-t \hat{f} r_{t}}{t f r_{t}}\right)^{2}+\sum_{t \in \mathbb{C}} \sum_{a=0}^{\Omega-1}\left(\frac{N_{a, t}-\hat{N}_{a, t}}{N_{t}}\right)^{2}+\sum_{t=t_{0}}^{T} \sum_{i=0}^{2}\left(\alpha_{t+1}^{i}-\alpha_{t}^{i}\right)^{2}+\left(\gamma_{t+1}^{i}-\gamma_{t}^{i}\right)^{2},
\end{aligned}
$$

subject to equations (3)-(4) and to

$$
f_{t, x}=\sum_{i} \alpha_{t}^{i} f_{x}^{(i)}, \quad\left(1-\pi_{t, x}\right)=\sum_{i} \gamma_{t}^{i}\left(1-\pi_{x}^{(i)}\right), \quad \sum_{i} \alpha_{t}^{i}=1, \quad \sum_{i} \gamma_{t}^{i}=1,
$$

where $\left\{\left\{\alpha_{t}^{i}, \gamma_{t}^{i}\right\}_{i=0}^{2}\right\}_{t=t_{0}}^{T}$ are the set of parameters for mortality and fertility, respectively; $f_{x}^{(i)}$ and $\pi_{x}^{(i)}$ are actual agespecific fertility rates and conditional survival probability by age for specific years; and $\mathbb{I} \equiv\{\mathbb{D}, \mathbb{B}, \mathbb{N}, \mathbb{E}, \mathbb{T}, \mathbb{C}\}$ are the sets of
} 
suffers from weak ergodicity, which implies that there are infinite initial population structures that are consistent with the final population. To avoid this problem, I calculated an initial population using "stable population theory" (Lotka, 1939), which is consistent with pre-demographic transition data in Taiwan (Lee et al., 2000, see Table 1). ${ }^{10}$ The results from the GIP model gives age-specific fertility rates $f_{t, x}$, conditional survival probabilities $\pi_{t, x}$, and population by age $\mathbf{N}_{t}$ from the year $1650\left(t_{0}\right)$ to the year 2009. Population projections from the year 2010 onwards are based on United Nations assumptions. After the year 2050 all vital rates are kept constant until the population becomes stable. Later on, the demographic information is used to reconstruct the household size (i.e., family scale) and the demographic relationships needed to calculate the familial transfers involved in the economic model (i.e., parenthood, number of offspring, siblings, etc.).

As a priori information, I collected data on population size, births, and deaths for the periods 19061942 and 1947-2005 from the Taiwan-Fukien Demographic Fact Book, the Ministry of the Interior R.O.C.; and for the year 2006 to the year 2009, from the Human Mortality Database (HMD). As population references, I use population by age for selected years $\{1956,1966,1970,1975,1980,1990,2000,2009\}$ taken from HMD. Age-specific fertility rates (ASFR) from 1962 to 2006 are taken from the Directorate-General of Budget, Accounting and Statistics, Executive Yuan (DGBAS) and death rates and life expectancy at birth are drawn from the HMD and the Human Life-Table Database. Life expectancy at birth and ASFR prior to 1926 and 1962 are based on data provided by Lee et al. (2000, see Figure 2). Crude migration rates are estimated using IP from 1905 to 2009 (see Figure 1(a)). Fitted demographic data are depicted in Figures 1(b)-1(d).

The discrepancy in the total fertility rate between the GIP estimates and those taken from Lee et al. (2000) are due to the introduction of migration. Lee et al. (2000) assumed a closed population, while I consider an open population for the population reconstruction. Thus, the immigration flow compensates for the lower fertility in order to maintain the same population size.

\subsection{Economy}

I calibrate the model to the Taiwanese economy using national accounts data from 1951 to 2009 published by the DGBAS. Capital share $\alpha$ is set to 0.26 , based on Young (1995). The subjective discount factor is set to one (Lee et al., 2000; Boucekkine et al., 2002), and the constant risk aversion coefficient is set to four (Lee et al., 2000). ${ }^{11}$ Capital stock is obtained by applying the perpetual inventory approach to gross fixed capital formation (GFCF) by category \{construction, transport equipment, machinery and equipment, and intangible fixed assets\}. The capital stock at the beginning of the period is computed as $K_{i}(0)=I_{i}(0) /\left(\delta_{i}+g_{i}\right)$, where $I_{i}(0)$ is the initial investment in category $i, \delta_{i}$ is the depreciation rate of category $i$, and $g_{i}$ is the growth rate of investment in the first 10 years in category $i$. The depreciation rates applied to each category are $2.1 \%, 18.2 \%, 13.8 \%$, and 15\%, respectively (Hulten and Wykoff, 1981). Using this information, I set the depreciation rate to $5 \%$, which is consistent with the average depreciation rate and the consumption of fixed capital formation (CFC) reported by the DGBAS for the

\footnotetext{
deaths, births, total population, life expectancy, total fertility rates, and censuses used in the calculation. Crude migration rates are obtained using inverse population projection and are exogenous to the GIP model.

${ }^{10}$ Based on Taiwanese data, Lee et al. (2000) observed an annual population growth rate of $1.1 \%$, a life expectancy at birth of 28.3 years, and a total fertility rate of six births per woman.

${ }^{11}$ A sensitivity analysis conducted for this variable showed that lower risk aversion values yield a higher capital-to-output ratio for the reference years, which does not match the actual capital-to-output data from the DGBAS.
} 


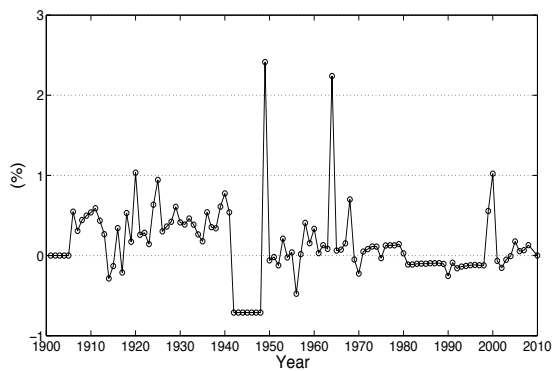

(a) Crude migration rate

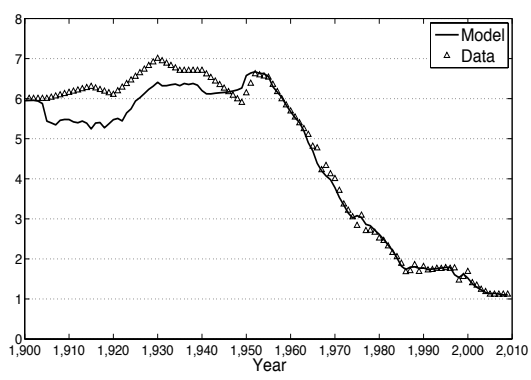

(c) Total fertility rate

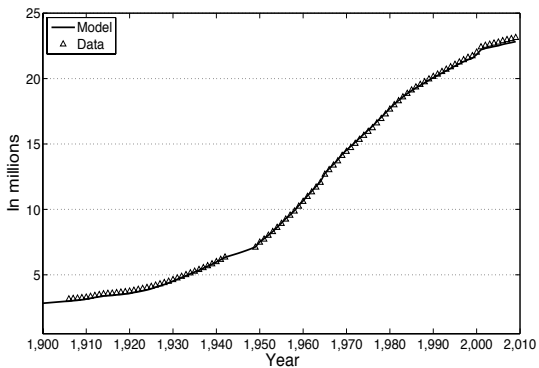

(b) Population size

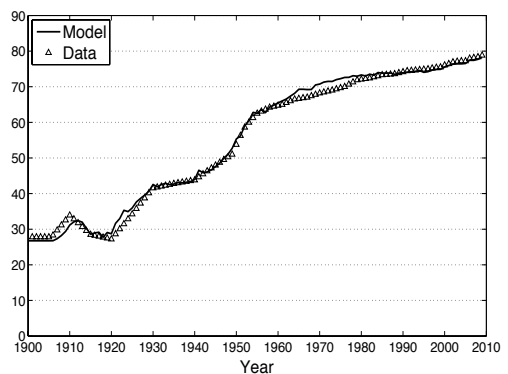

(d) Life expectancy at birth

Figure 1: Population Reconstruction, Taiwan 1900-2010

period 1960-2009. ${ }^{12}$ I calculated the labor-augmenting technological progress by applying the formula:

$$
\Gamma_{t}=1 /(1-\alpha) \ln Y_{t} / N_{t}-\alpha /(1-\alpha) \ln K_{t} / N_{t}-\ln H_{t} / N_{t},
$$

where $H_{t}$ is quality-adjusted aggregate labor input and $Y_{t}$ is GDP net of indirect taxes (Sun, 2006). Figure 2 depicts the estimated labor-augmenting technological progress. Before 1951, it is assumed that $\Gamma_{t}$ grows at an annual rate of $1.5 \%$, and after 2010 I assume that $\Gamma_{t}$ grows at an annual rate of $3 \%$, which is close to the average value between 1951 to 2009 .

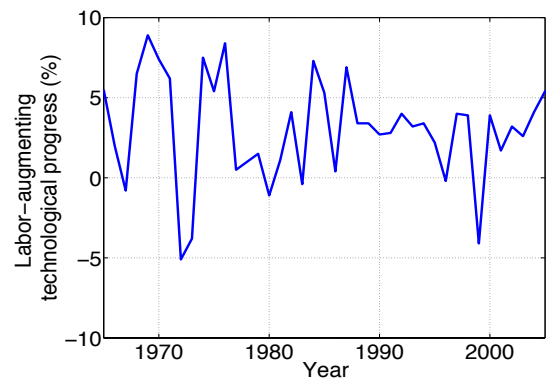

Figure 2: Labor-augmenting technological progress

Source: Author's calculations based on DGBAS data.

\footnotetext{
${ }^{12}$ The difference between the estimated and actual CFC gives an average error of $1 \%$ from 1966 to 2005 . Since the capital stock derived is insensitive to the method used after 15 years, I focus my analysis on the economic performance of Taiwan from 1965 to 2005 .
} 
The adjustment of the number of effective employees is calculated by combining age-efficiency profiles for different educational groups, $\left\{\epsilon_{x}^{j}\right\}_{x=T_{w}}^{T_{r}}$, obtained from Huang (2001, Table 11.3), educational distribution by birth cohort from Huang (2001, Table 11.1), employment rates by age from the DGBAS, $\left\{h_{t, x}\right\}_{x=T_{w}}^{T_{r}-1}$, and the working-age population from the demographic model. The educational distribution and age-specific productivity indexes are shown in Figure 3. I assume that the educational distribution does not change before the cohort born in 1926 and after the cohort born in $1970 .{ }^{13}$

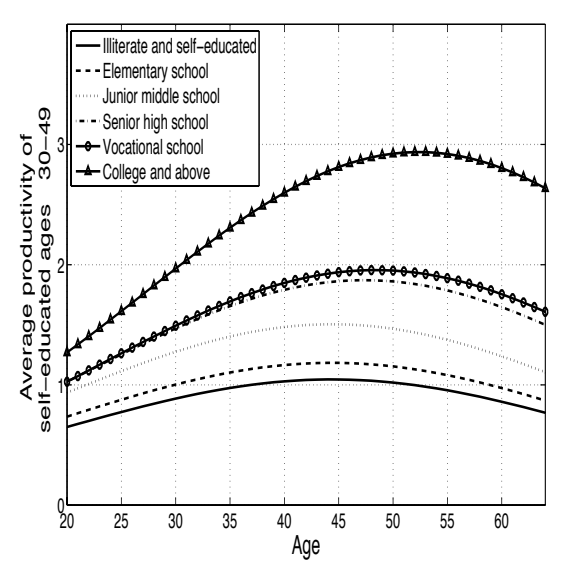

(a) Age-specific productivity index by educational attainment

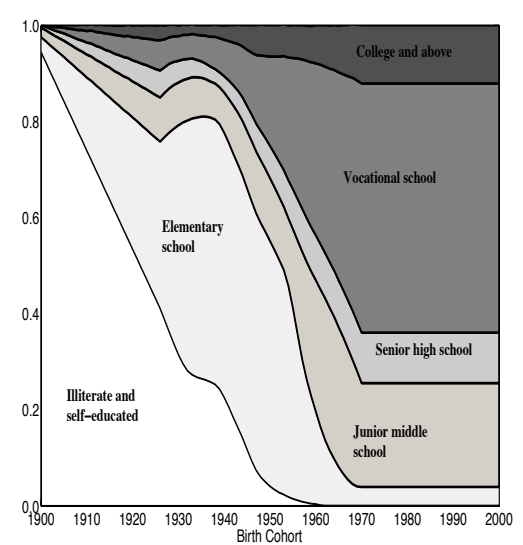

(b) The educational distribution

Figure 3: The educational distribution

Source: (Huang, 2001, Tables 11.1 and 11.3)

In this model, the rental price of capital is exogenous. Given that the capital share was roughly constant (Young, 1995; Hsieh, 2002), I calculated the rental price of capital from 1965 to 2009 using Equation (8). According to the dashed line in Figure 5(d), the average real interest rate from 1965 to 2009 was $10 \%$, starting at $18.4 \%$ in 1965 and rapidly declining to $4.5 \%$ in the year 2005 . This pattern is consistent with the hypothesis that factor accumulation largely explains the economic growth in Taiwan (Barro et al., 1995). Moreover, I also calculated the interest rate, assuming a closed economy for several reasons. First, this assumption was necessary in order to study the effect that openness had on Taiwan's economic growth and household saving. Second, I wished to compute the initial steady state of the economy before the demographic transition started. Third, since a reliable rental price of capital cannot be computed before year 1965, it was necessary to assume that the economy was closed until 1965 . Therefore, before 1965 I use the interest rate endogenously determined by the model assuming a closed economy.

Government consumption relative to output $\left(\eta_{t}\right)$, the capital income tax rate $\left(\tau_{k t}\right)$, and the labor income tax rate $\left(\tau_{l t}\right)$ from 1951 to 2009 is calculated using data from the DGBAS. The parametric components of the Taiwanese pension system are based on information reported by Tsui (2002). I set the proportion of income insured by the social insurance at $80 \%(\varpi)$, the number of years used for computing the pension benefits to three $\left(N_{b}\right)$, and the replacement rate to $15 \%(\psi)$. This last value corresponds to the sum of the replacement rates for the two major social insurance programs in Taiwan:

\footnotetext{
${ }^{13}$ This assumption does not change the results for the period analyzed: 1965-2005.
} 
Labor Insurance (LI) and Government Employee's Insurance (GEI). LI covers approximately 50\% of the working population, and its replacement rate is $20 \%$; while GEI covers $14 \%$ of the population, and provides retirement benefits with an average replacement rate of $40 \%(.5 \times .2+.14 \times .4 \approx .15)$.

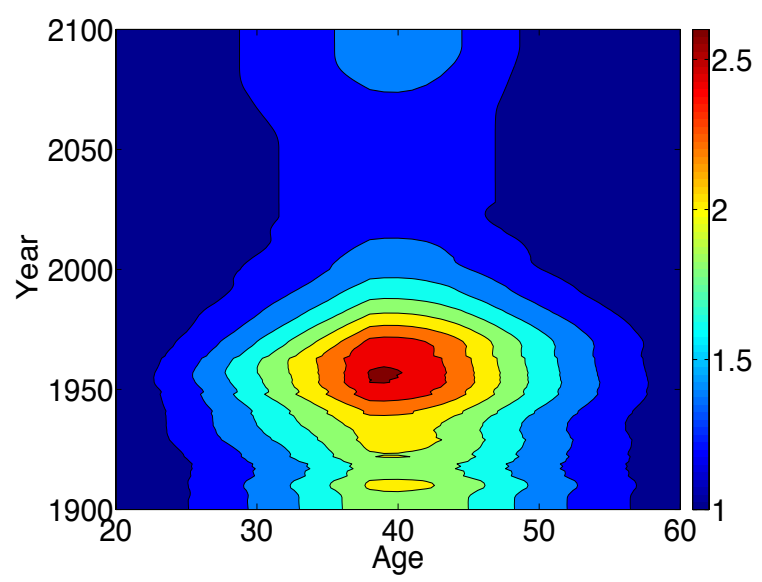

Figure 4: Number of equivalent adult consumers by age of household head, Taiwan 1900-2100 Source: Author's calculations.

Non-capital private transfers consist of childrearing costs, private health care, private education, and familial old-age support. I calculate average child-rearing costs as follows

$$
\lambda_{t, x}^{c}=\sum_{s=T_{w}}^{x} \frac{l_{t-x+s, s} f_{t-x+s, s}}{l_{t, x}} l_{t, x-s} \theta_{x-s} \cdot I_{x-s},
$$

where $\theta_{x}$ is a continuous scale that equals 0.4 from ages $0-4$, and rises with age until reaching one at the age of 18 (Mueller, 1976). $I_{x-s}$ is an index function that takes the value of one when $x-s$ is lower than $T_{w}$ and zero otherwise. Similarly, the cost of private health care and education for children is calculated by substituting $\theta$ with $\chi$. Given that $\chi$ values are not constant over time, and that NTA data do not cover the whole period analyzed, I calculated $\chi_{t, x}$ values, scaling at each period a common NTA profile to the total private expenditure on education and health care reported by the DGBAS. Following Chu and $\mathrm{Yu}$ (2007), the familial old-age support rate is set at 8.75\%, which is the average income transferred to elderly parents estimated from the Panel Study of Family Dynamics (PSFD).

Table 1 summarizes the model economy parameters.

\section{Matching the macroeconomic data of Taiwan}

Before explaining the contribution of demography to economic growth, it is crucial to demonstrate that this model is capable of reproducing actual national accounts data. Taiwan has been of special interest along with other East Asian economies, such as Hong Kong, South Korea, and Singapore, because of its surprisingly high output per capita growth, averaging a $6.2 \%$ per annum for four decades, and the sharp increase in saving, from $5 \%$ to over $30 \%$, after World War II.

Several attempts have been made to explain the rapid increase in saving rates in Taiwan for the period 1965-2000 (Kelley and Schmidt, 1996; Higgins and Williamson, 1997; Lee et al., 2000; Deaton and Paxson, 
Table 1: Model economy parameters

\begin{tabular}{|c|c|c|c|}
\hline & Symbol & Value & \\
\hline \multicolumn{4}{|l|}{ Household } \\
\hline Risk aversion & $\sigma$ & 4 & \\
\hline \multirow[t]{2}{*}{ Subjective discount factor } & $\beta$ & 1 & Lee et al. (2000) \\
\hline & & & and Boucekkine et al. (2002) \\
\hline Age at parental leave & $T_{w}$ & 20 & Lee et al. (2000) \\
\hline Retirement age & $T_{r}$ & 60 & Lee et al. (2000) \\
\hline \multicolumn{4}{|l|}{ Transfers } \\
\hline Consumption units & $\theta_{x}$ & & Mueller (1976) \\
\hline Private education and health & $\chi_{x}$ & & NTA and DGBAS \\
\hline Familial old-age support & $\pi^{\text {oas }}$ & $8.75 \%$ & Chu and Yu (2007) \\
\hline \multicolumn{4}{|l|}{ Technology } \\
\hline Capital share & $\alpha$ & 0.26 & Young (1995) \\
\hline Depreciation rate & $\delta_{t}$ & & DGBAS \\
\hline Rental price of capital & $r_{t}$ & & DGBAS \\
\hline Productivity & $A_{t}$ & & DGBAS \\
\hline Labor efficiency profile & $\epsilon_{x}$ & & Huang (2001) \\
\hline Educational attainment & $E_{t}$ & & Huang (2001) \\
\hline Employment rates & $h_{t, x}$ & & DGBAS \\
\hline \multicolumn{4}{|l|}{ Government } \\
\hline Public consumption to output & $\eta$ & & DGBAS \\
\hline Corporate income tax to output & $\tau_{k}$ & & DGBAS \\
\hline Labor income tax to output & $\tau_{l}$ & & DGBAS \\
\hline Number of years of contribution & $N_{b}$ & 3 & Tsui (2002) \\
\hline Pension replacement rate & $\psi$ & $15 \%$ & Tsui (2002) \\
\hline Labor income insured & $\varpi$ & $80 \%$ & Tsui (2002) \\
\hline
\end{tabular}


2000). However, all simulations failed in their attempt to replicate the evolution of saving. Similarly, the reasons behind the rapid growth in per capita output have been widely debated, with several explanations being suggested - such as productivity (Hsieh, 2002; Sun, 2006), input factor accumulation (Krugman, 1994; Young, 1995), and demography (Bloom and Williamson, 1998).

Table 2 shows the data collected from national accounts and the baseline results. The labor-augmenting technological progress averaged $2.9 \%$ for the period 1965-2005 and 3.2\% for the period 1965-1990; or, equivalently, there was a TFP growth rate of $2.4 \%$, which is slightly smaller than the rate reported by Hsieh (2002) and slightly higher than the rate reported by Young (1995). ${ }^{14}$ There are various reasons for the difference in productivity levels. First, the estimation method applied here does not account for the contribution of each industry in TFP; instead, it does so at an aggregate level. Second, the estimations include all sectors, whereas Young (1995) excludes agriculture. Last but not least, in order to be consistent with the theoretical model, $H_{t}$ does not take into account the number of hours worked. Aggregate capital accumulation and aggregate labor are, respectively, $1 \%$ and $0.5 \%$ smaller than those obtained by Young (1995, see Table IX).

Table 2: Macroeconomic Performance in Taiwan, 1965-2005.

\begin{tabular}{|c|c|c|c|c|c|c|c|c|}
\hline & $\begin{array}{c}\text { Output } \\
\text { per capita } \\
(Y / N)\end{array}$ & $\begin{array}{l}\text { Output } \\
(Y)\end{array}$ & $\begin{array}{c}\text { Capital } \\
(K)\end{array}$ & $\begin{array}{c}\text { Labor } \\
\text { Aug. } \\
(H)\end{array}$ & $\begin{array}{c}\text { Population } \\
(N)\end{array}$ & $\begin{array}{l}\text { Productivity } \\
(\Gamma)\end{array}$ & $\begin{array}{c}\text { Net } \\
\text { investment }\end{array}$ & $\begin{array}{c}\text { Household } \\
\text { saving }\end{array}$ \\
\hline \multicolumn{9}{|l|}{ Data } \\
\hline $1965-1970$ & 6.6 & 9.0 & 14.5 & 3.9 & 2.4 & 3.3 & 14.8 & 21.7 \\
\hline $1971-1980$ & 7.4 & 9.4 & 14.7 & 4.7 & 2.0 & 2.9 & 20.6 & 30.4 \\
\hline $1981-1990$ & 6.6 & 7.9 & 9.4 & 4.3 & 1.3 & 3.0 & 19.0 & 33.1 \\
\hline $1991-2000$ & 5.6 & 6.4 & 9.2 & 2.5 & 0.9 & 2.9 & 22.4 & 25.7 \\
\hline $2001-2005$ & 4.2 & 4.9 & 4.1 & 2.3 & 0.4 & 2.9 & 12.8 & 22.0 \\
\hline 1965-2005 & 6.2 & 7.6 & 10.6 & 3.6 & 1.4 & 2.9 & 18.8 & 27.6 \\
\hline \multicolumn{9}{|l|}{ Baseline } \\
\hline $1965-1970$ & 4.5 & 6.8 & 5.6 & 3.9 & 2.4 & 3.3 & 8.6 & 28.1 \\
\hline $1971-1980$ & 7.5 & 9.5 & 14.3 & 4.7 & 2.0 & 2.9 & 20.6 & 33.4 \\
\hline $1981-1990$ & 6.6 & 7.9 & 9.4 & 4.3 & 1.3 & 3.0 & 19.2 & 32.1 \\
\hline $1991-2000$ & 5.5 & 6.4 & 9.1 & 2.5 & 0.9 & 2.9 & 22.5 & 32.2 \\
\hline 2001-2005 & 4.5 & 4.9 & 4.0 & 2.3 & 0.4 & 2.9 & 12.8 & 26.0 \\
\hline 1965-2005 & 6.0 & 7.4 & 9.6 & 3.6 & 1.4 & 2.9 & 18.2 & 31.2 \\
\hline
\end{tabular}

Note: All values are percentages. The first six columns are annual growth rates. Source: Author's calculations based on information from the DGBAS.

Figure 5 displays the baseline economy results for the period 1965-2005. The figure is divided into four panels that show household savings behavior, net investment, the capital-output ratio, and the real interest rate. In Panels 5(a)-5(b), the solid-black line depicts the baseline economy results, while the observed statistics and those calculated from national accounts are represented by a dashed-blue line. Since our baseline model is based on national accounts data, in Panel 5(d) the rental price of capital is represented by a dashed-blue line instead. ${ }^{15}$

The baseline model reproduces the observed rates well. For instance, the baseline economy replicates perfectly net investment rates and capital-output ratios from 1970 to 2005 . Since both the capital share

\footnotetext{
${ }^{14}$ The values of TFP chosen correspond to those obtained using the primal approach.

${ }^{15}$ Using (5) and (8), the rental price of capital is given by $r_{t}+\delta_{t}=\alpha\left(Y_{t} / K_{t}\right)$.
} 


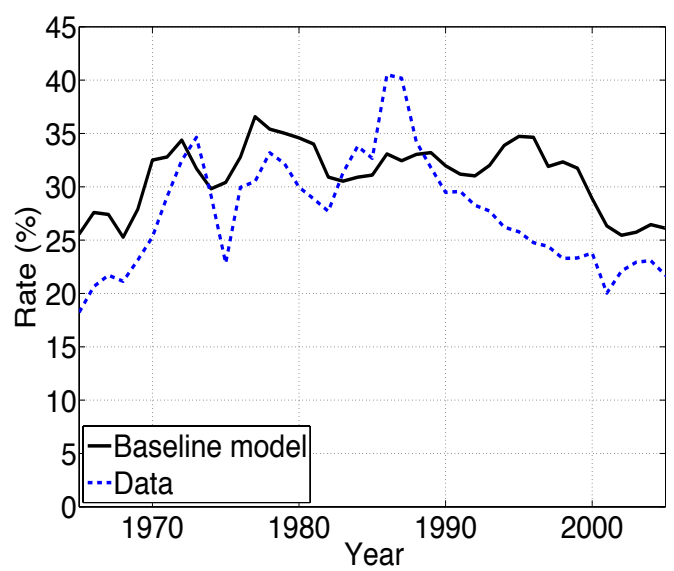

(a) Household saving rate

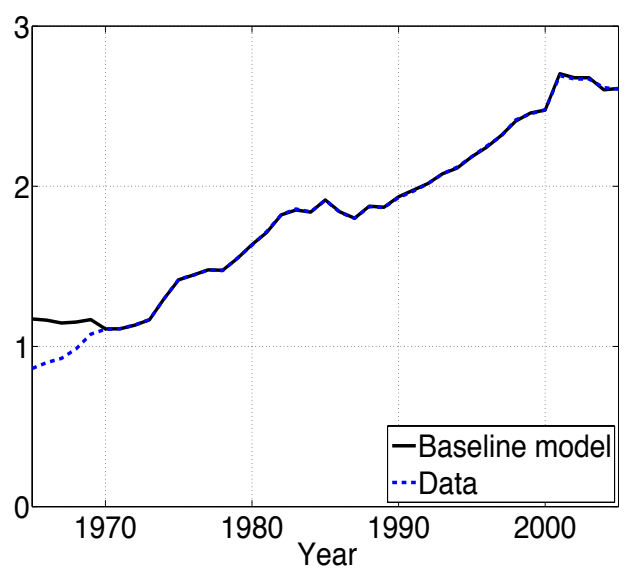

(c) Capital-output ratio

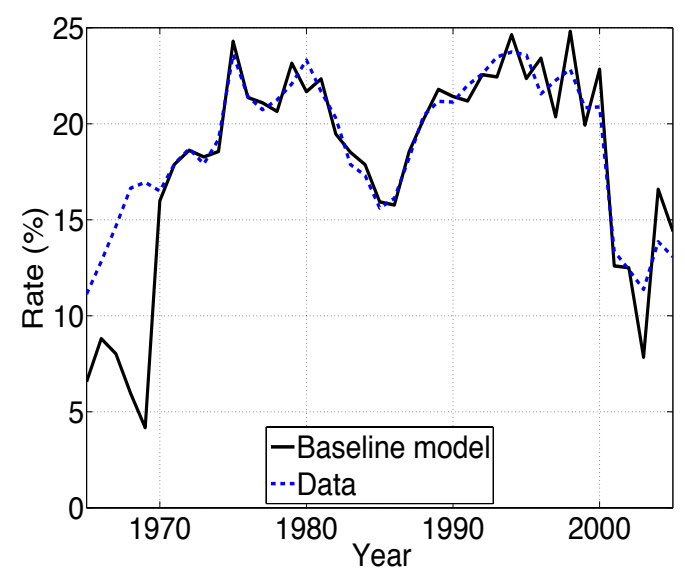

(b) Net investment rate

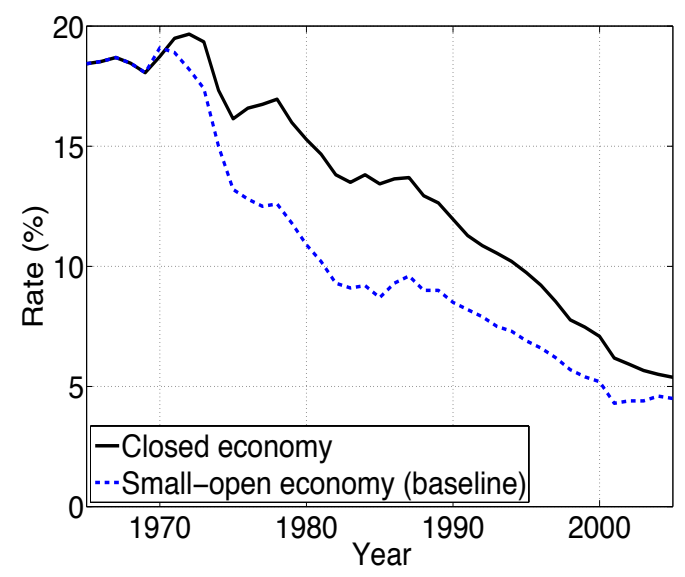

(d) Rental price of capital (net of depreciation)

Figure 5: In-sample performance of the model, Taiwan 1965-2005

Source: DGBAS and author's calculations.

Note: Following Deaton and Paxson (2000), household saving rates are calculated as private savings, divided by the sum of private savings plus private consumption. It should be noted that the sum of private savings plus private consumption can easily be derived by combining the market-clearing condition (24) and the government budget (17), which, under a constant returns to scale production function, is equal to household disposable income

$$
\left(1-\tau_{l t}\right) w_{t} H_{t}+\left(1-\tau_{k t}\right) r_{t} A_{t}=C_{t}+S_{t},
$$

where $A_{t}$ denotes households' financial wealth in year $t$, i.e. $A_{t}=K_{t}+F_{t}$. Therefore, household saving rate is equivalent to dividing the household's saving by the household's disposable income. Net investment rates are calculated as the net investment to output (net of capital depreciation) ratio, i.e., $\left(K_{t+1}-K_{t}\right) /\left(Y_{t}-\delta_{t} K_{t}\right)$. 
and the capital depreciation rate were roughly constant during the period analyzed (Hsieh, 2002), the fact that Taiwan was a small open economy caused these two macroeconomic variables to evolve in line with the internationally determined interest rate. By contrast, the fitting of output per capita growth (see the first column in Table 2) is due to the labor-augmenting technological progress and demographics. Panel 5(a) shows that household saving rates also increase from the 1960s to the 1990s, and slowly decline thereafter. Nevertheless, baseline household savings are on average 3.6\% higher than those observed in the actual national accounts (see the last column in Table 2). In Panel 5(d), a negative difference in interest rates between the baseline and the closed economy assumption can be seen, which corresponds to the fact that Taiwan is a net receiver of foreign capital during the period analyzed. ${ }^{16}$ Thus, the calibration strategy has been to find the elasticity of substitution that minimizes the difference between observed and simulated household savings and investment, and that preserves the net dependency on foreign capital. ${ }^{17}$

\section{Counterfactual experiments}

In this section, I investigate the contribution of fertility and mortality on income growth and saving rates. $^{18}$ To do so, I build four alternative demographies based on the underlying demographic data obtained in Section 3.1.

Experiment 1. (Vital rates fixed in 1965). I construct a population assuming that the vital rates in 1965 (i.e., mortality rates and fertility rates) would have remained constant after 1965. The new population grows in the long run at an annual rate of $2.75 \%$. Individuals have a life expectancy of 68 years and have an average of 2.45 children (or a TFR of 4.9 ).

Experiment 2. (Vital rates fixed in 1900). The assumptions are exactly the same as in Experiment 1 , but now I fix the vital rates in 1900. Individuals live from birth for an average of 27 years, and have three children (or a TFR of six). As a consequence, the population growth rate is equal to $1 \%$ per year. It should be noted that, although the life expectancy at birth is 27 years, once an individual survives to age five, he or she has nearly 41 remaining years of live.

Experiment 3. (Fixed mortality since 1900). This population is constructed by taking actual fertility and migration data and assuming that the mortality rates in 1900 are held constant over time. Thus, individuals have a life expectancy of 27 years, and, because fertility rates fall below replacement levels, population growth rates become negative from 1970 onwards.

Experiment 4. (Fixed fertility since 1900). This population projection assumes that fertility rates from 1900 are held constant over time, while mortality and migration rates are the observed rates. Life expectancy and migration rates are depicted in Panels 1(d) and 1(a), respectively. Under this scenario, a constant TFR of six, or three children per individual, yields positive and increasing population growth rates, with a final stable population growth of $3.75 \%$ per year.

\footnotetext{
${ }^{16}$ Indeed, net factor income from abroad represents around $2 \%$ annually of the output in Taiwan since the 1980 s.

${ }^{17}$ It should be noted that a higher elasticity of substitution yields not only a lower interest rate, but also the finding that Taiwanese households are net investors in foreign capital markets, which is not supported by SNA data.

${ }^{18}$ The same analysis has been done with migration. However, the contribution of this demographic process during the period analyzed (i.e., 1965-2005) is negligible. Thus, I opted to not report the results in the paper for the sake of space.
} 


\subsection{Demographics: The Role of Timing}

In the literature, two variables are frequently used to study the impact of demographic changes on economic growth: output per capita and investment. Output per capita growth is influenced by demography through changes in dependency rates. High youth dependency rates decrease per capita income growth because there are fewer producers relative to consumers, an effect known as the youth demographic burden (Bloom and Williamson, 1998). This occurs in the early phase of the demographic transition, when mortality declines and fertility remains high. When fertility starts falling, youth dependency rates decline and per capita income rises due to a rapid increase in the input factors (capital and labor). This second process is known as the first demographic dividend or demographic gift (Higgins and Williamson, 1997). Later, low fertility and mortality lead to an increase in the old-dependency rate. As a consequence, the share of the working-age population decreases, which, under the right policies, leads to an increase in capital per worker, an effect known as the second demographic dividend (Mason and Lee, 2006).

In a small open economy, investment is affected by demography through changes in the effective labor growth rate. ${ }^{19}$ It implies that one specific cohort affects investment rates from $T_{w}$ to $T_{r}$ years after being born. ${ }^{20}$ To illustrate this point, Panel 6(a) shows the growth rate of effective aggregate labor input under three different demographic scenarios: 1) baseline model or observed demography (black solid line); 2) Experiment 1: constant mortality and fertility rates as observed in 1965 from that period onwards (dash crossed red line); and 3) Experiment 2: constant mortality and fertility rates as in 1900 (solid circled red line). It can be seen that the difference in effective labor and investment rates between the observed demography and Experiment 1 is negligible during the first 20 years (see Panels 6(a) and 6(b)). However, by comparing the baseline model to Experiment 1, it becomes clear that the effective labor grew 2\%-2.5\% faster because of changes in demography, which raised investment on average by $4 \%$. After the year 1985 , Experiment 1 yields a higher effective aggregate labor, raising investment rates over rates in the baseline economy. From the years 1965 to 2005, the overall contribution of demography to investment is positive and equal to $16.6 \%$ using Experiment 2, while the contribution of demography turns out to be negative and smaller $(-10 \%)$ under Experiment 1 . This clearly show the errors made in attempts to measure the influence of demography on saving rates.

An identical timing effect is observed in per capita output growth $\left(\tilde{y}_{g r}\right)$. Following an approach similar to those of Bloom and Williamson (1998) and Kelley and Smith (2005), Equation (31) shows that the relationship between demography and output per capita is given by ${ }^{21}$

$$
\tilde{y}_{g r}=y_{g r}+H_{g r}-N_{g r},
$$

where subscript $g r$ denotes the growth rate and $y$ is effective output.

Table 3 reports the demographic contribution to per capita output growth. Like the effect on investment rates, the estimated contribution of demography on $g_{\tilde{y}}$ is smaller in Experiment 1 than in

\footnotetext{
${ }^{19}$ Assuming a Cobb-Douglas production function, investment rates are given by
}

$$
\frac{S_{t}}{Y_{t}-\delta_{t} K_{t}}=\frac{1}{\kappa_{t}^{\alpha-1}-\delta_{t}}\left(\frac{\kappa_{t+1}}{\kappa_{t}} \frac{\Gamma_{t+1}}{\Gamma_{t}} \frac{H_{t+1}}{H_{t}}-1\right),
$$

where $\kappa_{t}$ is effective capital in year $t$. It should be noted that, in a small open economy, effective capital is determined exogenously by competitive international capital markets, and $\Gamma_{t}$ is exogenously given in the model.

${ }^{20}$ In a closed economy, one cohort can influence the saving rate throughout their lifespan. However, the cohort members do not have a strong effect on effective capital until they enter the labor market.

${ }^{21}$ Unlike Equation (4) in Bloom and Williamson (1998, p. 431), in this model, the demographic contribution to output per capita is given by the productivity component and by the difference between the growth of the effective labor and the growth rate of the population (Kelley and Smith, 2005). 


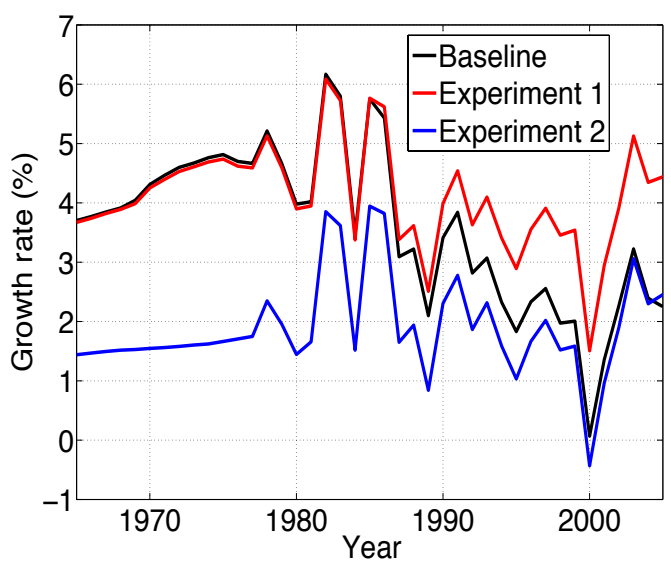

(a) Effective labor

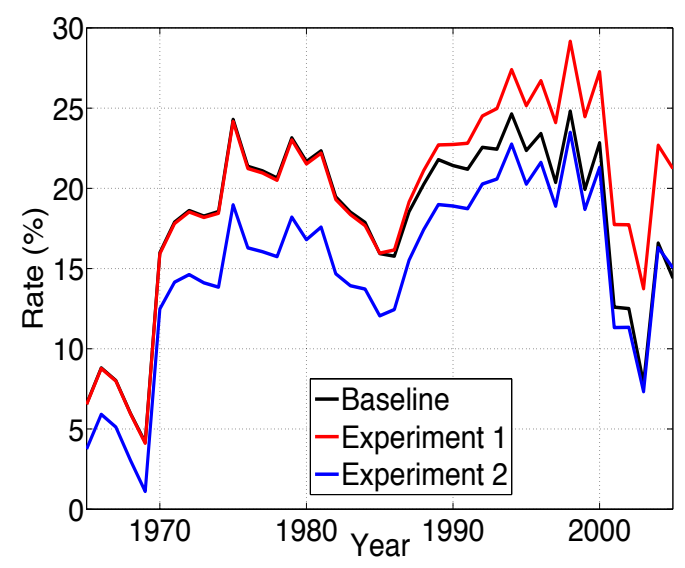

(b) Investment rates

Figure 6: Demographic impact on investment, Taiwan 1965-2005

Experiment 2. This is because population growth has an initial inertia, which makes the difference in $\tilde{y}_{g r}$ between the baseline model and Experiment 1 smaller than that in Experiment 2 during the first two decades; exactly the time newborns need to start entering the labor market.

Table 3: Demographic contribution to per capita output growth (in \%)

\begin{tabular}{|c|c|c|c|c|c|}
\hline & \multirow{2}{*}{$\begin{array}{c}\text { Baseline } \\
\tilde{y}_{g r}^{B} \\
\end{array}$} & \multicolumn{2}{|c|}{ Experiment 1} & \multicolumn{2}{|c|}{ Experiment 2} \\
\hline & & $\tilde{y}_{g r}^{1}$ & $\begin{array}{l}\text { Contribution } \\
100 \times \frac{\tilde{y}_{g r}^{B}-\tilde{y}_{g r}^{1}}{\tilde{y}_{g r}^{B}}\end{array}$ & $\tilde{y}_{g r}^{2}$ & $\begin{array}{l}\text { Contribution } \\
100 \times \frac{\tilde{y}_{g r}^{B}-\tilde{y}_{g r}^{2}}{\tilde{y}_{g r}^{B}}\end{array}$ \\
\hline $1965-1970$ & 4.5 & 4.0 & 10.2 & 3.4 & 23.6 \\
\hline $1971-1980$ & 7.5 & 6.4 & 15.1 & 5.4 & 28.1 \\
\hline 1981-1990 & 6.6 & 5.0 & 24.1 & 5.1 & 22.4 \\
\hline $1991-2000$ & 5.5 & 4.8 & 12.6 & 4.7 & 14.1 \\
\hline 2001-2005 & 4.5 & 3.9 & 13.4 & 3.7 & 17.8 \\
\hline 1965-2005 & 6.0 & 5.0 & 16.6 & 4.7 & 22.1 \\
\hline
\end{tabular}

Importantly, by using the correct counterfactual demography, i.e., Experiment 2, Table 3 shows that demography contributes $22 \%$ of the output per capita growth (period 1965-2005) in a small open economy, instead of the contribution of $16.6 \%$ estimated using Experiment 1.

\subsection{Demographics and per capita output growth}

To assess the effect that a demographic variable ' $\mathrm{x}$ ' has on output per capita growth, I assume that ' $\mathrm{x}$ ' had remained constant since the year 1900, whereas the rest of components are the observed ones. Then, for each demographic component, a new population is derived using Equation (3), i.e., Experiments 3 and 4. Before proceeding to comments on the results in Table 4, it is important to keep in mind that each demographic component does not affect economic growth linearly. Hence, the sum of the contribution to per capita output growth by each component does not necessarily need to match Experiment 2. 
Table 4: Contribution to per capita output growth by demographic component (in \%)

\begin{tabular}{|c|c|c|c|c|c|}
\hline & \multirow{2}{*}{$\begin{array}{c}\text { Baseline } \\
\tilde{y}_{g r}^{B}\end{array}$} & \multicolumn{2}{|c|}{ Experiment 3} & \multicolumn{2}{|c|}{ Experiment 4} \\
\hline & & $\tilde{y}_{g r}^{3}$ & $\begin{array}{l}\text { Contribution } \\
100 \times \frac{\tilde{y}_{g r}^{B}-\tilde{y}_{g r}^{3}}{\tilde{y}_{g r}^{B}}\end{array}$ & $\tilde{y}_{g r}^{4}$ & $\begin{array}{l}\text { Contribution } \\
100 \times \frac{\tilde{y}_{g r}^{B}-\tilde{y}_{g r}^{4}}{\tilde{y}_{g r}^{B}}\end{array}$ \\
\hline $1965-1970$ & 4.5 & 4.4 & 1.1 & 3.2 & 27.6 \\
\hline 1971-1980 & 7.5 & 7.1 & 5.6 & 5.5 & 26.5 \\
\hline 1981-1990 & 6.6 & 6.4 & 2.4 & 5.1 & 22.6 \\
\hline $1991-2000$ & 5.5 & 5.4 & 2.1 & 4.8 & 13.0 \\
\hline 2001-2005 & 4.5 & 4.4 & 2.3 & 3.8 & 16.1 \\
\hline 1965-2005 & 6.0 & 5.8 & 3.2 & 4.7 & 21.6 \\
\hline
\end{tabular}

Clearly, at least in a small open economy, fertility stands out as the main contributor to output per capita growth, while mortality has a small effect (see Table 4). ${ }^{22}$ This result is consistent with the "population revisionist" position (Bloom and Freeman, 1986; Brander and Dowrick, 1994; Barlow, 1994; Kelley and Schmidt, 1995; Bloom and Williamson, 1998). During the period 1965-2005, mortality had no impact on economic growth because mortality affects both the growth rate of the population and the growth rate of the effective labor. Thus, the positive effect of having more surviving workers is offset by the negative effect of more surviving children and women in their fertile years. ${ }^{23}$ In Taiwan, for instance, the infant mortality rate declined from 16.3 per thousand in the year 1970 to 5.4 per thousand in the year 2005. Unlike mortality, fertility does not affect the growth rate of the population to the same extent as the growth rate of workers. In general, a fertility increase raises the growth rate of the population in the short run, and then it raises the growth rate of workers, but not the growth rate of the population. As a consequence, a rapid fertility change has an initial negative economic effect (known as the youth dependency burden), and a subsequent positive economic impact, or demographic bonus, when the offspring enter the labor market. Table 4 shows how the fertility decline since the beginning of the 1950s affected output per capita growth positively during the period 1965-2005. Moreover, it should be noted that fertility peaked in the 1970s and 1980s, exactly when per capita output growth reached its maximum.

Before proceeding to the analysis of the impact of demography on investment and saving, it is important to remember that the impact of demography on the accumulation of capital is to some extent canceled out by the openness assumption. Indeed, by assuming a closed economy, additional simulations not presented in the paper show that the Taiwanese demography accounts for one-third of output per capita growth, with a small negative effect of mortality $(-4.4 \%)$ and a highly positive effect of fertility $(33.3 \%)$.

\subsection{Saving, investment, and demographics}

As was pointed out in the introduction, the most controversial area is the assessment of the role of demography on saving and investment. In particular, how does demography influence non-steady state saving and investment rates? Before addressing this question, I wish to summarize some of the most

\footnotetext{
${ }^{22}$ The same results are obtained running similar counterfactual simulations starting in 1925 and in 1950.

${ }^{23}$ Simulation results not presented here show that the impact of mortality is greater at the first and last stages of the demographic transition. This result is consistent with Braun et al. (2009) for Japan.
} 
recent results on this topic under steady state conditions. According to Williamson and Higgins (2001), there are two crucial variables: the population growth rate and the dependence on foreign capital. In the context of a closed economy inhabited by a population of overlapping generations, fertility changes have an ambiguous effect on the steady state capital (d'Albis, 2007). However, for observed historical population growth rates, fertility negatively affects the steady state capital because the capital dilution effect dominates the saving effect (Lau, 2009). Similarly, the impact of a change in mortality on the steady-state capital is ambiguous depending upon the age at which mortality improves. If mortality reductions happen after the reproductive span, population growth rate does not change, and so the saving effect dominates the capital dilution effect. If, however, mortality reductions happen before menopause, population growth rates change (since more fertile women survive), and the effect on the steady state capital therefore becomes ambiguous.

In contrast, if we assume an open economy with perfect international capital mobility, saving rates and investment rates are independent. Moreover, since the demand for financial wealth is independent of the capital stock, it is not guaranteed that the impact of demography on the investment rate will be the same as the effect on the saving rate. These two facts suggest the need for a separate analysis of each rate when one analyzes the impact of demography. On the one hand, according to Equation (30), the steady state investment rate is positively related to the population growth rate. Therefore, mortality reductions before menopause and lower fertility have an opposite effect on the steady state investment rate. It should also be noted that, since a mortality reduction after menopause does not modify population growth, the investment rate does not change. However, the population growth rate has an ambiguous effect on the steady state saving rate (Williamson and Higgins, 2001). The overall effect depends on what is known as the variable rate-of-growth effect (Fry and Mason, 1982; Mason, 1988).

It should be noted that these preliminary and theoretical results indicate that, regardless of the dependence on foreign Capital, both mortality and fertility have an effect on saving and investment, while Section 5.2 shows that mortality has almost no effect on per capita output growth during the period analyzed. Second, the relationships stated above between demographics and both saving and investment rates correspond to steady state economies. Surprisingly, the steady state analysis has been frequently used to analyze transitional dynamics. However, the relationships under this setup do not necessarily hold during transition dynamics. Third, dependent children are in general not considered in the economy. As a consequence, we find a continuous underestimation of the effect of demography on saving rates (Curtis et al., 2011; Braun et al., 2009; Lee et al., 2000).

In this subsection, I extend the work done by Williamson and Higgins (2001) on saving and investment behaviors during the demographic transition. Specifically, I focus on the differential effect of mortality and fertility on saving and investment rates during the period 1965-2005 in Taiwan. To compare the differential effect of demography on saving and investment under different capital mobility assumptions, I include three more simulations in which I assume a closed economy. To empirically illustrate the results, Panels 7(a)-7(d) show under open and closed economies the effect of both demographic changes on saving and investment rates in Taiwan.

Case: Small open economy. In Panel 7(a), Experiment 3 (circled solid line) and Experiment 4 (crossed solid line) are compared to the baseline model (blue solid line). It should be noted that rates lower (higher) than the baseline rates mean a positive (negative) effect. This relationship is similar in all panels, regardless of whether I refer to saving or investment. Consistent with Equation (30), lower mortality raises investment rates by 5.5 percentage points, while lower fertility decreases investment rates 
by 2.6 percentage points (see the first column in Table 5). Interestingly, under a small open economy, the effect of lower mortality and lower fertility on saving is positive (see Panel 7(b)), 1.5\% and 3.1\% respectively - which supports the dependence hypothesis (Coale and Hoover, 1958). Moreover, comparing the effect of each component on saving and investment provides additional insights. For instance, the fact that lower fertility has a negative effect on investment and a positive effect on saving suggests that the stock of capital increases at the expense of households' financial wealth. In other words, since under a small open economy the investment rate is solely influenced by the capital dilution effect, the change in sign suggests that the saving effect dominates the capital dilution effect. Specifically, the saving effect represents a total change of $5.7 \%(\approx 3.1-(-2.6)$ ), while the capital dilution effect is equal to $-2.6 \%$ (see the last row, columns 1 and 2, Table 5). The overall effect of demographics on saving is $5.8 \%$ and $3 \%$ on investment, which corresponds to a variation of $18.3 \%$ and $16.6 \%$, respectively, with respect to the baseline (see first row, columns 1 and 2, in Table 5).

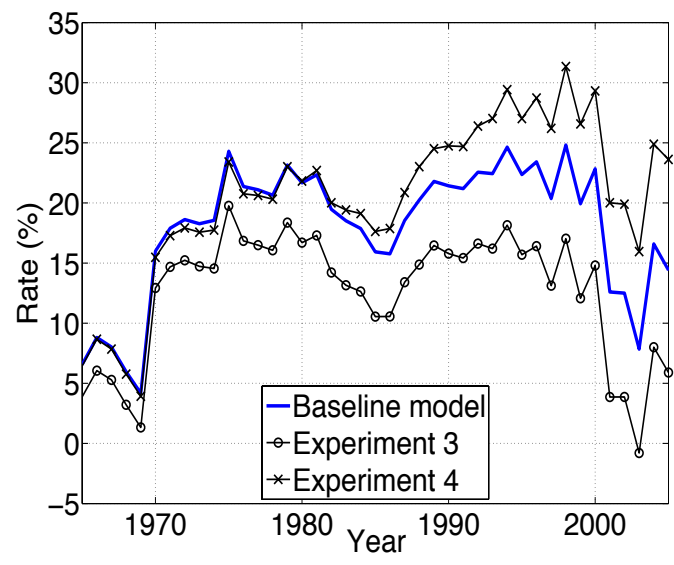

(a) Small open economy, Investment

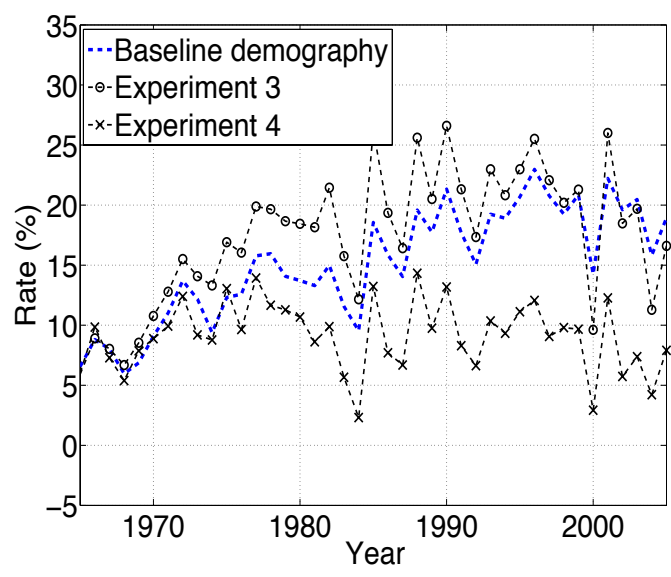

(c) Closed economy, Investment

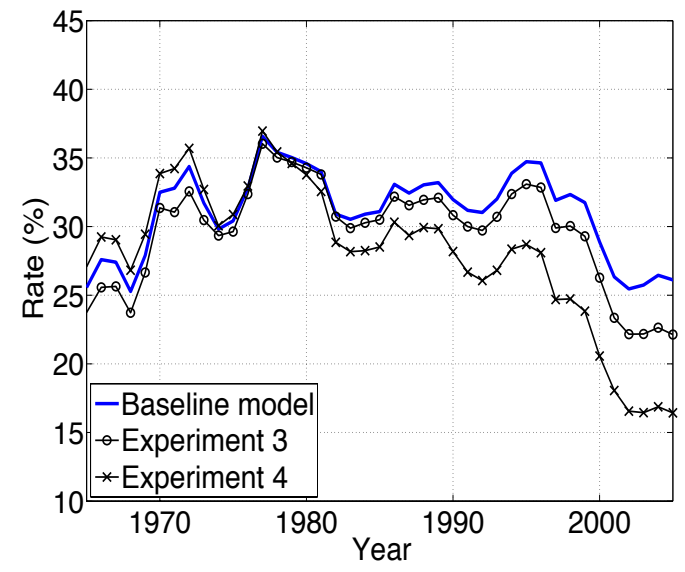

(b) Small open economy, Saving

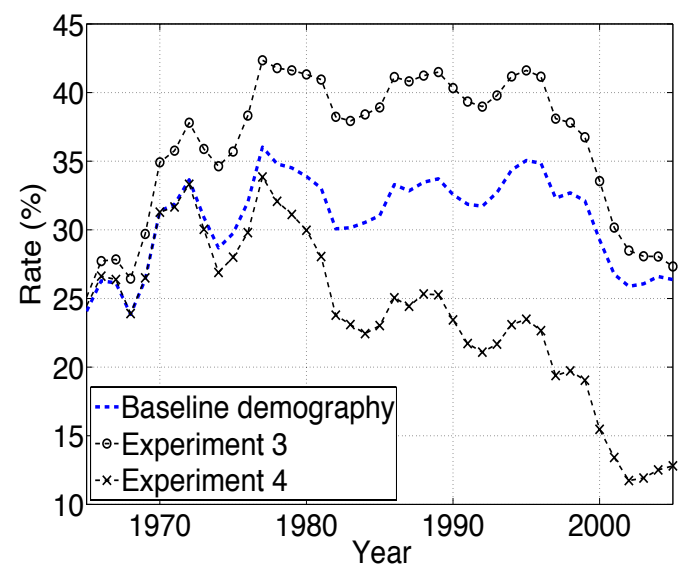

(d) Closed economy, Saving

Figure 7: Demographic Impact of Fertility and Mortality on Saving and Investment, Taiwan 1965-2005

Note: The net effect of a demographic change is given by the difference between the experiment and the baseline. Experiment 3 refers to a population in which life expectancy has not changed since 1900, while Experiment 4 refers to a population in which fertility rates have not changed since 1900. 
Table 5: Absolute change in saving and investment rates by demographic component and dependency on foreign capital (in \%), Taiwan 1965-2005

\begin{tabular}{lcc|cc}
\hline \hline & \multicolumn{2}{c|}{$\begin{array}{c}\text { Small open economy } \\
\text { Investment }\end{array}$} & \multicolumn{2}{c}{ Saving } \\
\cline { 2 - 5 } Experiment 2 & 3.0 & 5.8 & 10.3 & 11.3 \\
& & & & \\
Experiment 3 (mortality) & 5.5 & 1.5 & -2.3 & -5.6 \\
Experiment 4 (fertility) & -2.6 & 3.1 & 6.1 & 7.1 \\
\hline
\end{tabular}

Source: Author's calculations. Note: Results presented in this table correspond to effects depicted in Panels $7(\mathrm{~b})-7(\mathrm{c})$ and not to the final steady state economy. Under a closed economy, the impact of mortality and fertility reductions on steady state saving and investment rates are found to be positive.

Case: Closed economy. It is well known that, under a closed economy, the impact of each demographic variable affects saving and investment similarly (see panels $7(\mathrm{c})-7(\mathrm{~d})$ ). To better distinguish between closed and open economies, I use dashed lines in panels 7 (c) and 7(d). Table 5 reports that lower mortality negatively affects investment and saving ( $-2.3 \%$ and $-5.6 \%$, respectively), while lower fertility boosts them ( $6.1 \%$ and $7.1 \%$, respectively). Therefore, under a closed economy the two demographic components have opposite effects.

The difference in saving under a closed and an open economy stems from the difference in the relative price of input factors. In particular, Experiment 3 reports slightly higher interest rates than the baseline economy before the 1970s and slightly lower interest rates after the 1990s. The difference in interest rates between Experiment 4 and the baseline economy diverges after 1975, with a steady state interest rate that is equal to 18\%. Under Experiment 2, the interest rate is always higher than the baseline and any other experiment. As a result, the overall effects of the two demographic processes are to raise investment and saving rates by $10 \%$ and $11 \%$, respectively.

From this analysis, some interesting conclusions can be drawn. First, the Taiwanese demography has contributed significantly to the increases in investment (16.4\%) and saving (18.5\%) from 1965 to 2005. Second, the impact of demography on investment and saving was muted by the dependence on foreign capital. Indeed, under a closed economy, demographic changes would have raised investment by two-thirds and saving by one-third. Nevertheless, this result does not imply that openness would not have contributed to economic growth. On the contrary, further simulation results also show that the overall per capita output growth rate would have been slightly lower. Fourth, the impact of fertility and mortality on investment and saving vary depending upon the dependence on foreign capital. And fifth, the dependency hypothesis coined by Coale and Hoover (1958) is confirmed.

\section{Conclusion}

The common approach to measuring the economic-demographic connection in computable OLG growth models is to run counterfactual experiments fixing vital rates (i.e., fertility and mortality rates) at the beginning of the economic analysis (Chen et al., 2006, 2007; Braun et al., 2009). This paper shows that this commonly used procedure leads to an underestimation of the effect of demography on economic 
growth. In order to correct this problem, I show that it is necessary to have demographic data at least one generation before the period analyzed, which is exactly the time needed for a newborn to enter the labor market.

With sufficient demographic information, the results obtained in this paper are similar to those estimated using "convergence models" (Bloom and Williamson, 1998; Kelley and Smith, 2005). In particular, I find that demography accounts for $22 \%$ of Taiwan's per capita output growth, $16.4 \%$ of the increase in investment, and $18.5 \%$ of the increase in saving during the period 1965-2005.

In line with previous literature, the counterfactual experiments conducted show that fertility is the most important demographic factor in explaining the increase in per capita output growth, and that mortality has no significant influence on this economic variable from 1965 to 2005. However, the effect of demography on saving and investment is less straightforward. Assuming a small open economy, I find that investment rates increase with more rapid population growth, while saving rates are explained by the dependence hypothesis (Coale and Hoover, 1958; Williamson and Higgins, 2001). On the contrary, under a closed economy, lower mortality and lower fertility have the opposite effect on saving and investment rates.

\section{References}

Attanasio, O. P. and G. Weber (2010, September). Consumption and saving: Models of intertemporal allocation and their implications for public policy. Journal of Economic Literature 48, 693-751.

Barlow, R. (1994, March). Population growth and economic growth: Some more correlations. Population and Development Review 20(1), 153-165.

Barro, R. J., N. G. Mankiw, and X. Sala-I-Martin (1995). Capital mobility in neoclassical models of growth. The American Economic Review 85(1), 103-115.

Barro, R. J. and X. Sala-i-Martín (2004). Economic Growth (Second Edition ed.). London: The MIT Press.

Bloom, D. E. and R. B. Freeman (1986, September). The effects of rapid population growth on labor supply and employment in developing countries. Population and Development Review 12(3), 381-414.

Bloom, D. E. and J. G. Williamson (1998, September). Demographic transitions and economic miracles in emerging asia. The World Bank Economic Review 12(3), 419-455.

Boucekkine, R., D. de la Croix, and O. Licandro (2002). Vintage human capital, demographic trends, and endogenous growth. Journal of Economic Theory 104, 340-375.

Brander, J. A. and S. Dowrick (1994, February). The role of fertility and population in economic growth: Empirical results from aggregate cross-national data. Journal of Population Economics 7(1), 1-25.

Braun, A. R., D. Ikeda, and D. H. Joines (2009, January). The saving rate in Japan: Why it has fallen and why it will remain low. International Economic Review 50(1), 291-321.

Browning, M. and A. Lusardi (1996, December). Household saving: Micro theories and micro facts. Journal of Economic Literature 34 (4), 1797-1855. 
Chen, K., A. Imrohoroglu, and S. Imrohoroglu (2006, December). The japanese saving rate. The American Economic Review 96(5), 1850-1858.

Chen, K., A. İmrohoroğlu, and S. İmrohoroğlu (2007). The Japanese saving rate between 1960 and 2000: Productivity, policy changes, and demographics. Economic Theory 32, 87-104.

Chu, C. Y. C. and R.-R. Yu (2007). Allocating Public and Private Resources across Generations, Volume 2, Chapter Kinship Network and Intergenerational Transfers.

Coale, A. J. and E. Hoover (1958). Population Growth and Economic Development in Low-Income Countries. Princenton, N.J.: Princeton University Press.

Curtis, C. C., S. Lugauer, and N. C. Mark (2011, February). Demographic patterns and household saving in china. NBER Working Paper Series (16828), 1-21.

d'Albis, H. (2007, January). Demographic structure and capital accumulation. Journal of Economic Theory 132(1), 411-434.

Deaton, A. and C. Paxson (2000). Growth, demographic structure, and national saving in Taiwan. Population and Development Review 26, 141-173.

Díaz-Giménez, J. and J. Díaz-Saavedra (2009). Delaying retirement in spain. Review of Economic Dynamics 12, 147-167.

Directorate-General of Budget, Accounting and Statistics, Executive Yuan (Varios years). Taiwan-Fukein Demographic Fact Book, R.O.C.. Data available at http://stat.gov.tw.

Feeney, G. and A. Mason (2001). Population Change and Economic Development. Challenges Met, Oportunities Seized., Chapter Population in East Asia, pp. 61-95. Contemporary Issues in Asia and the Pacific. Stanford University Press.

Feyrer, J. (2007). Demographics and productivity. Review of Economics and Statistics 89(1), 1000-1009.

Fry, M. and A. Mason (1982). The variable rate-of-growth effect in the life-cycle saving model. Economic Inquiry 20(3), 426-442.

Gersovitz, M. (1988). Saving and development. In H. Chenery and T. Srinivasan (Eds.), Handbook of Development Economics, Volume 1, Chapter 10, pp. 381-424. Elsevier Science Publisher B.V.

Goldberger, A. (1973, March). Depedency rates and saving rates: Further comment. American Economic Review 63(1), 232-233.

Hayashi, F. and E. C. Prescott (2002). The 1990s in Japan: A lost decade. Review of Economic Dynamics 5, 206-235.

Higgins, M. and J. G. Williamson (1997). Age structure dynamics in asia and dependence on foreign capital. Population and Development Review 23(2), 261-293.

Hsieh, C.-T. (2002, June). What explains the industrial revolution in east asia? evidence from the factor markets. The American Economic Review 92(3), 502-526. 
Huang, F.-M. (2001). Population Change and Economic Development. Challenges Met, Oportunities Seized., Chapter Education, Earning, and Fertility in Taiwan, pp. 279-299. East-West Center Series on Contemporary Issues Asia and the Pacific. Stanford University Press.

Hulten, C. R. and F. C. Wykoff (1981). Depreciation, Inflation, and the Taxation of Income from Capital, Chapter The Measurement of Economic Depreciation, pp. 81-125. Washington, D.C: Urban Institute.

Human Life-Table Database (2011). Max Planck Institute for Demography Research (Germany), University of California, Berkeley (USA), and Institut National D'études Démographiques (France). Data available at http://www.lifetable.de.

Human Mortality Database (2010). University of California, Berkeley (USA), and Max Planck Institute for Demography Research (Germany). Available at www.mortality.org or www.humanmortality.de (data download on February 2010).

Kelley, A. C. and R. M. Schmidt (1995, November). Aggregate population and economic growth correlations: The role of the components of demographic change. Demography 32(4), 543-555.

Kelley, A. C. and R. M. Schmidt (1996). Saving, dependency and development. Journal of Population Economics 9(4), 365-386.

Kelley, A. C. and R. M. Smith (2005). Evolution of recent economic-demographic modeling: A synthesis. Journal of Population Economics 18(2), 275-300.

Krueger, D. and A. Ludwig (2006, November). On the consequences of demographic change for rates of returns to capital, and the distribution of wealth and welfare.

Krugman, P. (1994). The myth of asia's miracle. Foreign Affairs 73(6), 62-78.

Lau, S.-H. P. (2009). Demographic structure and capital accumulation: A quantitative assesment. Journal of Economic Dynamics and Control 33, 554-567.

Lee, R. D. (1985). Inverse projection and back projection: A critical appraisal, and comparative results for england, 1539 to 1871. Population Studies 39, 233-248.

Lee, R. D. (2003). The demographic transition: Three centuries of fundamental change. The Journal of Economic Perspectives 17(4), 167-190.

Lee, R. D., A. Mason, and T. Miller (2000). Life cycle saving and the demographic transition: The case of Taiwan. Population and Development Review 26, 194-219.

Lee, R. D., A. Mason, and T. Miller (2001). Population Change and Economic Development. Challenges Met, Oportunities Seized., Chapter Saving, Wealth, and the Demographic Transition in East Asia, pp. 155-184. Contemporary Issues in Asia and the Pacific. Stanford University Press.

Lee, R. D., A. Mason, and T. Miller (2003). Population Matters. Demographic Change, Economic Growth, and Poverty in the Developing World, Chapter Saving, Wealth, and Population, pp. 137-164. Oxford University Press.

Lee, Y.-J., W. L. Parish, and R. J. Willis (1994, January). Sons, daughters, and intergenerational support in Taiwan. The American Journal of Sociology 99(4), 1010-1041. 
Leff, N. H. (1969). Dependency rates and savings rates. The American Economic Review 59(5), 886-896.

Leslie, P. H. (1945). On the use of matrices in certain population dynamics. Biometrika 33, $183-212$.

Lotka, A. J. (1939). Theorie Analytique des Associations Biologiques. Part. II. Analyse Demographique avec Application Particuliere a l'Espece Humaine. Number 780. Paris: Hermann et Cie.

Mason, A. (1988, March). Saving, economic growth, and demographic change. Population and Development Review 14(1), 113-144.

Mason, A. (2001). Population Change and Economic Development. Challenges Met, Oportunities Seized., Chapter Population and Economic Growth in East Asia, pp. 1-30. Contemporary Issues in Asia and the Pacific. Stanford University Press.

Mason, A. and R. D. Lee (2006). Reform and support systems for the elderly in developing countries: capturing the second demographic dividend. GENUS LXII(2), 11-35.

Modigliani, F. (1970). The life-cycle hypothesis and intercountry differences in the saving ratio. In W. A. Eltis, M. F. Scott, and J. N. Wolfe (Eds.), Induction, Growth, and Trade: Essays in Honour of Sir Roy Harrod, pp. 197-225. Oxford: Oxford University Press.

Modigliani, F. and R. Brumberg (1954). Utility Analysis and the Consumption Function: An Interpretation of Cross Section Data (New Brunswick, N. J. ed.). Post Keynesian Economics. Rutgers University Press.

Mueller, E. (1976). Population and Development: The Search for Selective Interventions, Chapter The Economic Value of Children in Peasant Agriculture., pp. 98-153. Baltimore: Johns Hopkins University Press.

Oeppen, J. (1993). Back projection and inverse projection: Members of a wider class of constrained projection models. Population Studies 47, 245-267.

Poterba, J. M. (2001, November). Demographic structure and asset returns. The Review of Economics and Statistics 83(4), 565-584.

Preston, S. H., P. Heuveline, and M. Guillot (2002). Demography: Measuring and Modeling Population Processes. Massachusetts: Blackwell Publishers Inc.

Ram, R. (1982, June). Dependency rates and aggregate savings: A new international cross-section study. American Economic Review 72(3), 537-544.

Ríos-Rull, J.-V. (2001, May). Population changes and capital accumulation: The aging of the baby boom. Advances in Macroeconomics 1(1), Article 7.

Sun, C.-H. (2006). Imperfect competition, economic miracle, and manufacturing productivity growth: Empirical evidence from taiwan. Atlantic Economic Journal 34, 341-359.

Tsui, S. W. (2002). Reforming the pension systems in taiwan: Options and challenges. Hitotsubashi Journal of Economics 43(2), 87-104.

United Nations (2011, January). Department of Economics and Social Affairs, Population Division, World Population Prospects: The 2008 Revision. Data available at http://esa.un.org/unpp. 
Williamson, J. G. and M. Higgins (2001). Population Change and Economic Development. Challenges Met, Oportunities Seized., Chapter The Accumulation and Demography Connection in East Asia, pp. 123-154. Contemporary Issues in Asia and the Pacific. Stanford University Press.

Yaari, M. (1965, April). Uncertain lifetime, life insurance, and the theory of the consumer. The Review of the Economic Studies 5(3), 304-317.

Young, A. (1995). The tyranny of numbers: Confronting the statistical realities of the east asian growth experience. The Quarterly Journal of Economics 110(3), 641-680.

\section{Sensitivity analysis}

In this section, I investigate how sensitive the model is to alternative specifications. I also report the results of three other simulations. In Figure 8, I introduce two simulations that maintain the baseline assumptions, but use two opposing cases of how children are considered in the model: i) no family scale (circled red line) and ii) altruism towards dependent children (squared green line). Like Curtis et al. (2011), I find that the 'no kids' saving rate is higher than the baseline during the period analyzed. Indeed, saving rates are on average overstated by $19 \%$ with respect to the baseline model. Nevertheless, in this case, it is important to note that the timing of changes in saving rates are not modified, and that this assumption does not influence steady state values. In the second simulation, I consider the same instantaneous utility function as in Lee et al. (2000)

$$
u\left(\lambda_{t, x}^{c}, c_{t, x}^{j}\right)=\left(1+\lambda_{t, x}^{c}\right) u\left(c_{t, x}^{j}\right) \text { with } u^{\prime}>0 \text { and } u^{\prime \prime}<0,
$$

which implies that household utility is proportional to the number of equivalent adult consumers in the household. This modification implies that household heads are altruistic towards their dependent children, raising total resources spent on children at the expense of saving. Thus, Figure 8 shows that saving rates only decrease by $4 \%$.

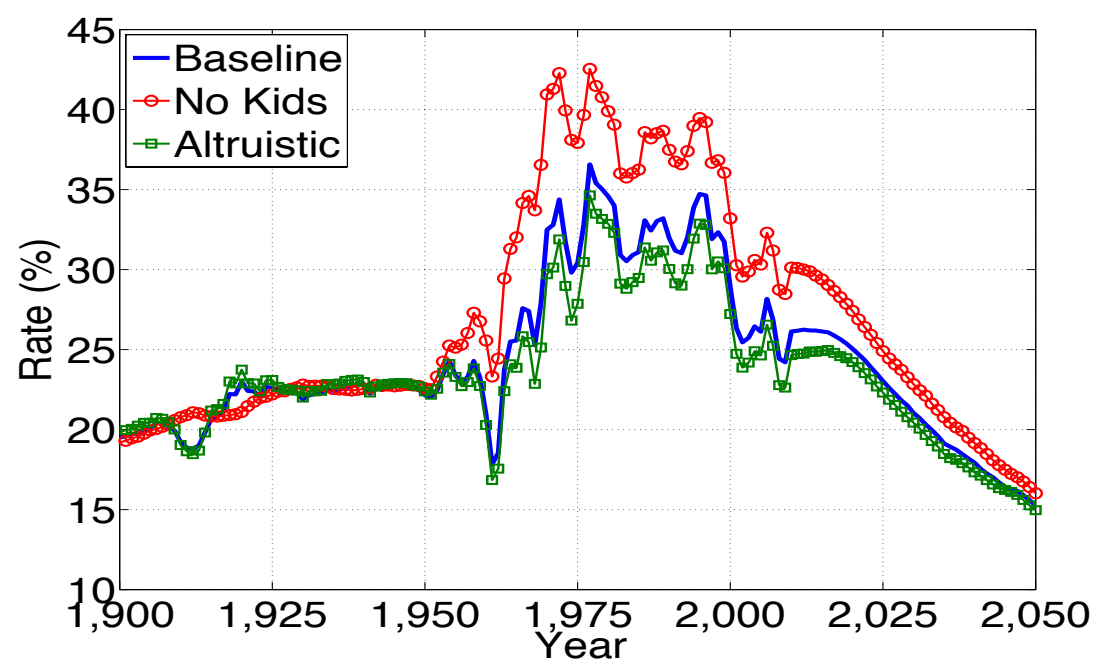

Figure 8: Family scale and altruism, Taiwan 1900-2050 
The third simulation shows the effect of a lower relative risk aversion coefficient on saving rates $(\sigma=2)$, see Figure 9. Besides the difference in saving rates, a lower risk aversion coefficient implies, under a closed economy, a higher capital-to-output ratio, and hence lower interest rates. The difference in interest rates between open and closed economies would have been positive, implying that Taiwanese households were net exporters of capital. This contrasts radically with national accounts data.

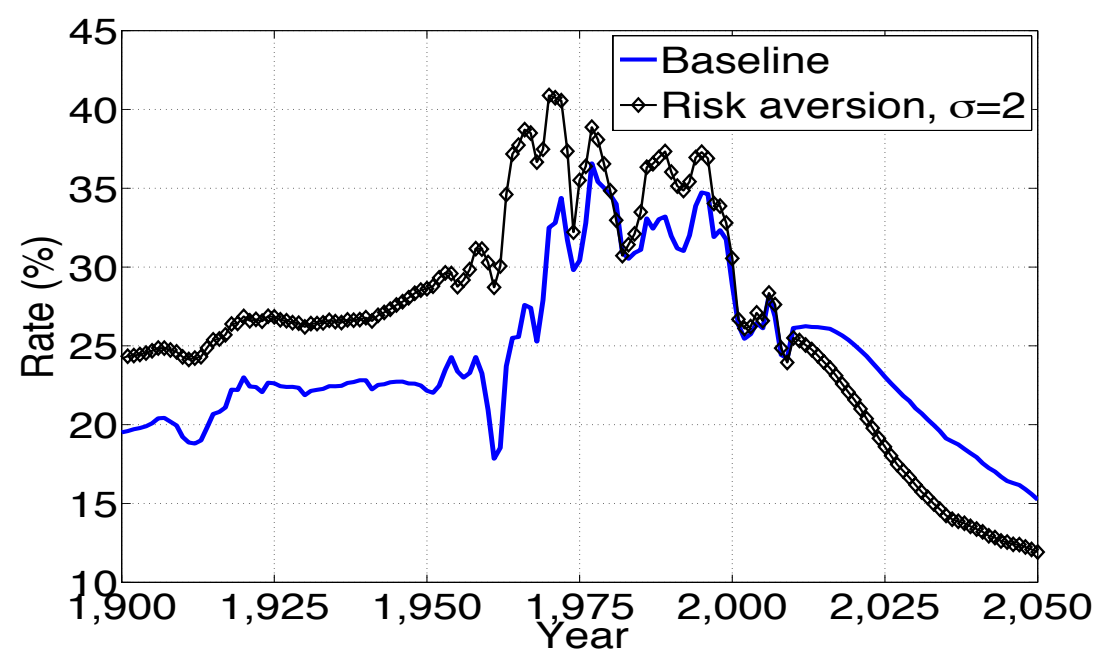

Figure 9: Variations on the relative risk aversion, Taiwan 1900-2050 


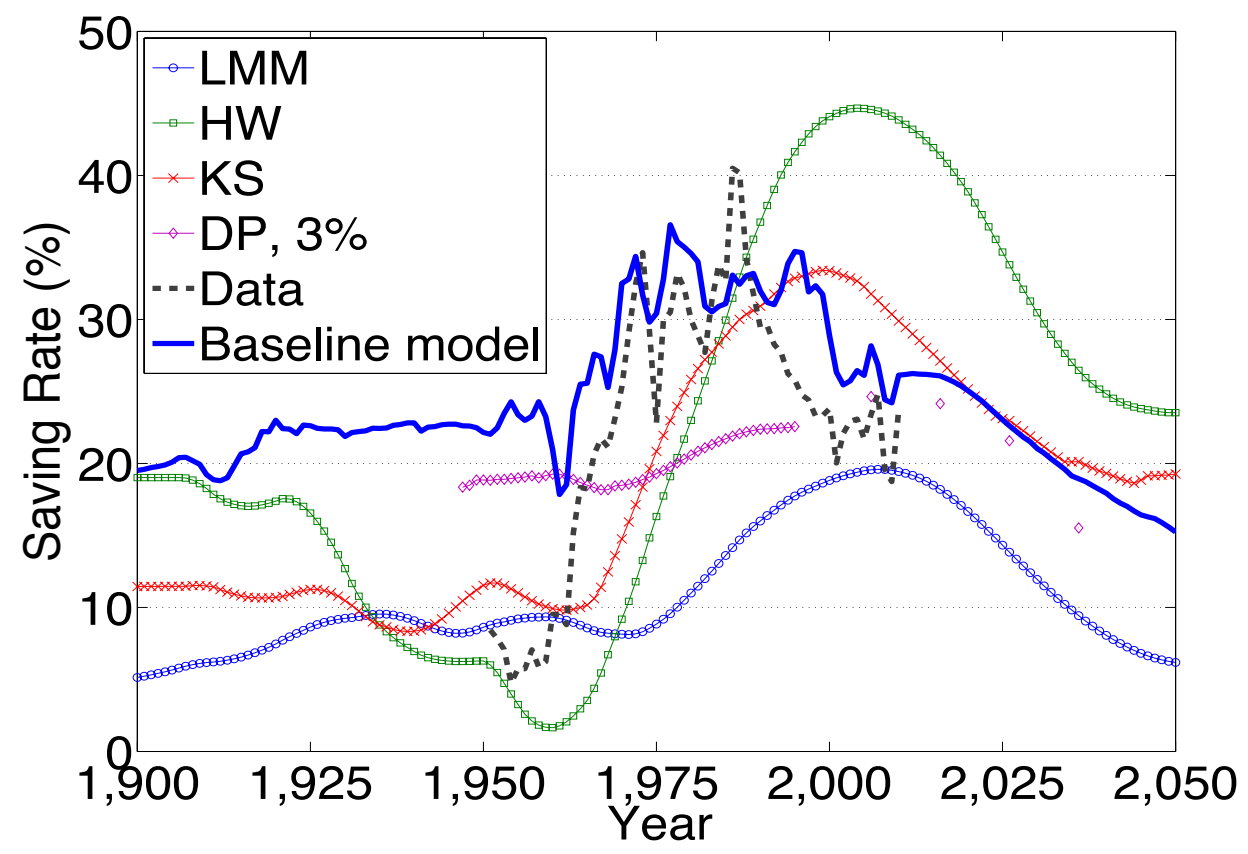

Figure 10: Simulated demographic effects on aggregate savings based on fifth methods, Taiwan 1900-2050 Sources: Based on Figure 7 in (Lee et al., 2000, p. 213).

Note: LMM: Lee et al. (2000); HW: Higgins and Williamson (1997); KS: Kelley and Schmidt (1996); DP: Deaton and Paxson (2000); Data: Actual household saving rates. 